\title{
ABT737 reverses cisplatin resistance by targeting glucose metabolism of human ovarian cancer cells
}

\author{
YUNJIE XU ${ }^{1}$, WEINAN GAO ${ }^{2}$, YONG ZHANG ${ }^{1}$, SHANSHAN WU $^{1}$, YANAN LIU ${ }^{1}$, XINYUE DENG $^{1}$, \\ LILI XIE ${ }^{3}$, JIAYAN YANG ${ }^{1}$, HUIMEI YU ${ }^{1}$, JING SU ${ }^{1}$ and LIANKUN SUN ${ }^{1}$ \\ ${ }^{1}$ Department of Pathophysiology, Basic College of Medicine, Jilin University; ${ }^{2}$ School of Clinical Medicine, Jilin University; \\ ${ }^{3}$ Department of Oral Geriatrics, School and Hospital of Stomatology, Jilin University, Changchun, Jilin 130021, P.R. China
}

Received November 7, 2017; Accepted June 20, 2018

DOI: 10.3892/ijo.2018.4476

\begin{abstract}
The poor prognosis and high mortality of patients with ovarian cancer result in part from their poor response to platinum-based chemotherapy. However, the precise mechanism behind cisplatin resistance is still not fully understood. In the present study, the authors explored the mechanism of resistance to cisplatin from the perspective of glucose metabolism in human ovarian cancer. The experiments using genetically matched ovarian cancer cell lines SKOV3 (cisplatin-sensitive) and SKOV3/DDP (cisplatin-resistant) in the present study provided some important findings. First, in comparison to SKOV3 cells, SKOV3/DDP cells exhibited decreased dependence on aerobic glycolysis and an increased demand for glucose. Secondly, the stable overexpression of Bcl-2 and ability to shift metabolism towards oxidative phosphorylation (OXPHOS) in SKOV3/DDP cells were associated with increased oxygen consumption. Furthermore, the metabolic characteristic of elevated OXPHOS primarily comprised most mitochondrial-derived reactive oxygen species (ROS) and, at least in part, contributed to the slight pro-oxidant state of SKOV3/DDP cells in turn. Thirdly, SKOV3/DDP cells reset the redox balance by overexpressing the key enzyme glucose 6-phosphate dehydrogenase (G6PD) of the pentose phosphate pathway to eliminate the cytotoxicity of highly elevated ROS. Furthermore, the inhibition of Bcl-2 reduced the OXPHOS
\end{abstract}

Correspondence to: Professor Jing Su or Professor Liankun Sun, Department of Pathophysiology, Basic College of Medicine, Jilin University, 126 Xinmin Street, Changchun, Jilin 130021, P.R. China E-mail: sunlk@jlu.edu.cn

E-mail: sujing@jlu.edu.cn

Abbreviations: Bcl-2, B-cell lymphoma 2; Bcl-w, BCL-2 like protein 2; Bcl-xL, B-cell lymphoma extra large; OXPHOS, oxidative phosphorylation; ATP, adenosine triphosphate; ECAR, extracellular acidification rate; OCR, oxygen consumption rate; ROS, reactive oxygen species; TCA, tricarboxylic acid cycle

Key words: Bcl-2 family, oxidative phosphorylation, cancer metabolism, reactive oxygen species, cisplatin resistance, ovarian cancer cells and sensitivity of SKOV3/DDP cells to cisplatin in a selective manner. Furthermore, when combined with 2-deoxyglucose (2-DG), the anticancer effect of the Bcl-2 inhibitor ABT737 was greatly potentiated and hypoxia-inducible factor $1 \alpha$ (HIF-1 $\alpha$ ) appeared to be closely associated with Bcl-2 family members in the regulation of glucose metabolism. These results suggested that the special glucose metabolism in SKOV3/DDP cells might be selectively targeted by disrupting Bcl-2-dependent OXPHOS.

\section{Introduction}

Cisplatin is one of the most widely used chemotherapeutics and has been applied for treating ovarian cancer. However, resistance to cisplatin can develop, which results in poor prognosis and high patient mortality $(1,2)$. Over the last 40 years, many biological analyses of the mechanism of cisplatin resistance have been performed, and it is now recognized to be more complicated than originally thought. Mechanisms of cisplatin resistance in many types of cancer were thought to be associated with enhanced drug efflux, reduced drug uptake, repair of DNA adducts, and evasion of apoptosis $(3,4)$. In addition, previous studies by the authors demonstrated that cisplatin resistance in ovarian cancer cells was associated with increased autophagic degradation of ubiquitinated proteins (5), enhanced lysosomal function in cisplatin-induced autophagic processes (6), and close communication between the endoplasmic reticulum (ER) and mitochondria that was induced by the overexpression of $\mathrm{Bcl}-2$ (7).

Members of the B-cell lymphoma 2 (Bcl-2) protein family are the major regulators of the apoptotic process, and the prosurvival members of this family (Bcl-2, Bcl-w and Bcl-xL) that inhibit apoptosis are overexpressed in many types of cancer. The altered expression of the pro-survival members of the Bcl-2 has been reported to be associated with resistance to cytotoxic antineoplastic drugs (8-11). The mechanisms by which Bcl-2 family proteins regulate apoptosis were thought to depend primarily on their ability to modulate the release of apoptosis-associated proteins (12). Consistent with mitochondria being the major sites of activity of members of the Bcl-2 protein family, studies have suggested that the overexpression of Bcl-2 and Bcl-xL are also able to stimulate mitochondrial respiration, with increases in the activity of complex I, oxygen 
consumption, adenosine triphosphate (ATP) levels, and mitochondrial transmembrane potential $(\Delta \Psi \mathrm{m})$ in osteosarcoma and lung cancer cells $(13,14)$. Therefore, apart from their role in the apoptotic process, the anti-apoptotic members of the Bcl-2 family may also have additional roles associated with mitochondrial metabolism to regulate cell fate.

It was previously hypothesized that cancer cells are highly dependent on aerobic glycolysis to survive, which is also termed the 'Warburg effect' $(15,16)$. However, recent studies have demonstrated that the sources of ATP from mitochondria are also of great importance to cancer cells (17). Recently, evidence in support of the hypothesis that resistance to cytotoxic antineoplastic drugs induces a metabolic shift from aerobic glycolysis towards oxidative phosphorylation (OXPHOS) has been presented (18-20), demonstrating that metabolic plasticity has an important role in tumor recurrence. However, research on the metabolic changes in cisplatinresistant ovarian cancer cells (C13) has indicated increased dependence on glucose and reduced oxygen consumption compared with those in cisplatin-sensitive (2008) cells (21). Therefore, the metabolic phenotypes of drug-resistant cancer cells may differ for different drugs or cancer cell lines.

ABT-737, a powerful inhibitor of anti-apoptotic proteins, $\mathrm{Bcl}-2$, Bcl-xL, and Bcl-w, displays synergistic cytotoxicity (9) and induces considerable apoptosis in assorted cancer types, including ovarian cancer, cholangiocarcinoma and lung cancer $(7,22)$. Moreover, the authors of the present study previously found that ABT737 was able to enhance cisplatininduced apoptosis by regulating ER-mitochondrial $\mathrm{Ca}^{2+}$ signal transduction or modulating mitochondrial dynamics in ovarian cancer cells $(7,22)$. Based on the roles of pro-survival members of Bcl-2 family in mitochondrial metabolism, it was proposed that ABT737 might affect resistance to cisplatin by modulating glucose metabolism in human ovarian cancer cells.

The data reported in the present study indicated that glucose demand in human ovarian cancer SKOV3/DDP (cisplatin-resistant) cells increased, and metabolism shifted in these cells towards OXPHOS via the stable overexpression of Bcl-2. Furthermore, inhibiting Bcl-2 reduced OXPHOS and selectively sensitized SKOV3/DDP cells to cisplatin. The combination of inhibiting Bcl-2 and glycolysis dramatically decreased the survival of SKOV3/DDP cells. Therefore, targeting Bcl-2 family members may be a promising approach for treating ovarian cancer. Furthermore, in the modulation of cancer glucose metabolism, pro-survival members of Bcl-2 family appear to be closely related to hypoxia-inducible factor $1 \alpha(\mathrm{HIF}-1 \alpha)$.

\section{Materials and methods}

Reagents and antibodies. The stock solutions of ABT-737 were prepared in DMSO (Selleck Chemicals, Houston, TX, USA). Cisplatin, 2-deoxy-2-[(7-nitro-2,1,3-benzoxadiazol-4-yl) amino]-D-glucose (2-NBDG), Rotenone and 6-aminonicotinamide (6-AN) were from Sigma-Aldrich (Merck KGaA, Darmstadt, Germany). MitoSOX Red (mitochondrial superoxide indicator) and MitoTracker Green were purchased from Invitrogen (Thermo Fisher Scientific, Inc., Waltham, MA, USA). Carbonyl cyanide p-trifluoromethoxyphenylhydrazone (FCCP) and antimycin A were purchased from Abcam
(Cambridge, MA, USA). 2-deoxy-D-glucose (2-DG), rotenone and dehydroepiandrosterone (DHEA) were from Aladdin industrial Corporation (Shanghai, China). 2',7'-Dichlorofluorescin diacetate (DCFH-DA) was purchased from Beyotime Institute of Biotechnology (Shanghai, China). Anti-HK2 (cat. no. 22029-1-AP), anti-Bcl-2 (cat. no. 12789-1-AP), antiG6PD (cat. no. 25413-1-AP), anti- $\beta$-actin (cat. no. 60008-1-Ig) and anti-PDHB (cat. no. 14744-1-AP) antibodies were purchased from ProteinTech Group, Inc., (Chicago, IL, USA) $(1: 1,000)$. Anti-HIF-1 $\alpha$ (1:200; cat. no. sc-10790) and anti-Glut1 (1:200; cat. no. sc-7903) were purchased from Santa Cruz Biotechnology, Inc., (Dallas, TX, USA). Peroxidase-conjugated AffiniPure goat anti-rabbit IgG (H+L; cat. no. SA00001-2) and peroxidase-conjugated AffiniPure goat anti-mouse IgG $(\mathrm{H}+\mathrm{L}$; cat. no. SA00001-1) from ProteinTech Group, Inc.

Cell culture. Human ovarian carcinoma cell lines SKOV3 (cisplatin-sensitive) and SKOV3/DDP (cisplatin-resistant) cells were obtained from the Chinese Academy of Medical Sciences and Peking Union Medical College (Beijing, China). The two cell lines were maintained in Roswell Park Memorial Institute-1640 (RPMI-1640) culture medium (Gibco Life Technologies, Carlsbad, CA, USA) supplemented with $10 \%$ fetal bovine serum (FBS, Invitrogen; Thermo Fisher Scientific, Inc.), $100 \mathrm{U} / \mathrm{ml}$ penicillin, and $100 \mathrm{mg} / \mathrm{ml}$ streptomycin (complete medium) at $37^{\circ} \mathrm{C}$ and $5 \% \mathrm{CO}_{2}$ with high humidity. To maintain resistance to cisplatin, SKOV3/DDP cells were cultured in complete medium with $1 \mu \mathrm{g} / \mathrm{ml}$ cisplatin (Sigma-Aldrich, Merck KGaA) (6).

Cell viability assays. Cell viability was determined by MTT assay. The cells were seeded in 96-well plates with $100 \mu 1$ complete RPMI- 1640 medium at $8 \times 10^{3}$ per cells/well. Following overnight incubation at $37^{\circ} \mathrm{C}$, increasing concentrations of cisplatin were applied followed by culture at $37^{\circ} \mathrm{C}$ for $24 \mathrm{~h}$. For each group, replicate experiments were performed in five wells. A total of $20 \mu \mathrm{l}$ MTT was added to each well and incubated for $4 \mathrm{~h}$. Then, $150 \mu \mathrm{l}$ DMSO was added to each well to dissolve the formazan crystals. The absorbance at $570 \mathrm{~nm}$ was determined using a microplate reader (BioTek Instruments, Inc., Winooski, VT, USA).

Glucose metabolism RT2 profiler polymerase chain reaction (PCR) array. The expression levels of 84 key genes in glucose metabolism were determined by Human Glucose Metabolism $\mathrm{RT}^{2}$ Profiler $^{\mathrm{TM}}$ PCR Array (SABiosciences; Qiagen $\mathrm{GmbH}$, Hilden, Germany). Total RNA was isolated from cultured cells, and $1 \mu \mathrm{g}$ of total RNA was reverse-transcribed to singlestranded cDNA using the RT ${ }^{2}$ First Strand kit (SABiosciences; Qiagen $\mathrm{GmbH}$ ). The expression levels of genes of interest were determined by quantitative PCR using the Applied Biosystems 7300 Fast Real-Time PCR system (Thermo Fisher Scientific, Inc.) with SYBR Green fluorophore using the RT2 SYBR Green Master Mix (SABiosciences; Qiagen GmbH). The reaction program involved 40 cycles of $95^{\circ} \mathrm{C}$ for $10 \mathrm{~min}$, $95^{\circ} \mathrm{C}$ for $15 \mathrm{sec}$ and $60^{\circ} \mathrm{C}$ for $1 \mathrm{~min}$. The results were analyzed using the manufacturer's software and relative gene expression was quantified using the $2^{-\Delta \Delta \mathrm{Cq}}$ method (23). The altered expression of the 84 genes was displayed using heat imaging with normalization to $\beta$-actin. 
Reverse transcription-quantitative polymerase chain reaction $(R T-q P C R)$. In accordance with the manufacturer's protocol, total RNA of cultured cells was extracted using TRIzol (Invitrogen, Thermo Fisher Scientific Inc.). A total of $1 \mu \mathrm{g}$ RNA was reverse-transcribed to cDNA using SuperScript ${ }^{\mathrm{TM}}$ IV First-Strand Synthesis System (Invitrogen, Thermo Fisher Scientific Inc.). The relative expression of genes of interest was determined with StepOne ${ }^{\mathrm{TM}}$ Real-Time PCR system and Power SYBR ${ }^{\circledR}$ Green PCR Master Mix (Applied Biosystems; Thermo Fisher Scientific Inc.) on an ABI 7300 instrument. The $\mathrm{RT}$ reaction was initially run at $50^{\circ} \mathrm{C}$ for $10 \mathrm{~min}$, followed by a denaturation step at $94^{\circ} \mathrm{C}$ for $2 \mathrm{~min}$. Also, the amplification reaction was continued for 35 cycles of denaturing $\left(94^{\circ} \mathrm{C}\right.$ for $\left.15 \mathrm{sec}\right)$ and annealing $\left(55^{\circ} \mathrm{C}\right.$ for $\left.30 \mathrm{sec}\right)$, followed by final extending step at $68^{\circ} \mathrm{C}$ for $1 \mathrm{~min}$. The primer sequences are listed in Table I.

Oxygen consumption and extracellular acidification rates. The rates of oxygen consumption (OCR) and extracellular acidification were determined using the fluorescent oxygensensitive and $\mathrm{pH}$-sensitive probes Mito-Xpress and $\mathrm{pH}-\mathrm{Xtra}$ (Luxcel Bioscience, Cork, Ireland). Briefly, SKOV3 or SKOV3/ DDP cells were seeded in 96-well plates at $8 \times 10^{4}$ cells/well. Following overnight incubation at $37^{\circ} \mathrm{C}$, different drug treatments were applied followed by culture for $6 \mathrm{~h}$. For each group, replicate experiments were performed in three wells (24).

Glucose, lactate concentrations and glucose uptake. The cells were seeded in 6 -well plates at $5 \times 10^{5}$ cells per well. Following overnight incubation at $37^{\circ} \mathrm{C}$, the medium was changed to fresh complete medium. After $24 \mathrm{~h}$, the medium of the cells was collected after which the proteins were extracted by sonication and quantified using the Bradford Protein Assay kit (Beyotime Institute of Biotechnology). Then, the glucose and lactate concentrations were determined using glucose assay (RsBio, Shanghai, China) and lactate assay kits (Jiancheng Bio, Nanjing, China), respectively. The untreated groups were collected and measured using 2-NBDG $(50 \mu \mathrm{M}$; Sigma-Aldrich; Merck KGaA) in Dulbecco's modified Eagle's medium (Gibco Life Technologies; without serum and glucose) for $30 \mathrm{~min}$ to determine the capacity for glucose uptake using a flow cytometer (BD Biosciences, Franklin Lakes, NJ, USA).

ATP assay of cell viability and glycogen concentration. A total of $1 \times 10^{6}$ cells were plated in a $25 \mathrm{~cm}^{2}$-cell culture flask. Following overnight incubation at $37^{\circ} \mathrm{C}$, the medium was changed to fresh medium. After $24 \mathrm{~h}$, in accordance with the manufacturer's instructions, cells were washed with PBS and then their ATP levels were determined by CellTiter-Glo ${ }^{\circledR}$ Luminescent Cell Viability Assay (Promega, Madison, MI, USA). The glycogen concentrations were determined from the cell lysate using a glycogen assay kit (Jiancheng Bio) in accordance with the manufacturer's protocol.

Western blot analysis. Western blot determination of cell extracts was measured as described previously (25). After different treatments, the SKOV3 or SKOV3/DDP cells were harvested and washed with cold phosphate-buffered saline (PBS), and then incubated in ice-cold radioimmunoprecipitation assay buffer. The cell lysates were sonicated and centrifuged at $5,000 \mathrm{x} \mathrm{g}$ for $10 \mathrm{~min}$. The concentration of the protein was
Table I. Primer sequences.

Primer name Primer sequence (5'-3')

\section{HK2}

Forward

Reverse

GAGCCACCACTCACCCTACT

GPI

Forward CCAGGCATTCGGCAATGTG

Reverse

GCTTTGCTGCGTACTTCCA

PFKL

Forward GTCCACACGGGTTCCAGA

Reverse

GGCTTCGACACCCGTGTAA

G6PD

Forward

Reverse

CGTCAAACCTCTTGTCATCCA

\section{PDHB}

Forward

ATGGCAGAGCAGGTGGCCCT

TCATGCAGGACTCGTGAATG

Reverse

GTAGAGGACACGGGCAAGAT

TTCACGAACTGTCAACTGCAC

LDHA

Forward

Reverse

TTGACCTACGTGGCTTGGAAG

CS

Forward GGTAACGGAATCGGGCTGAAT

Reverse

TCCGACCCTTACCTGTCCTT ACTTCCTGATTTGCCAGTCC

$\mathrm{ACO} 2$

Forward

AGATTGTGTATGGACACCTGGA

Reverse

TACGACTTGCCTCGCTCAAT

IDH2

Forward

Reverse

CCATCATCTGCAAAAACATCC

CCAATGGTGATGGGCTTG

MDH2

Forward

CAGGACCAGCTGACAGCAC

Reverse AGCCTGCTCCGGCTTTAG

GYS

Forward

GCCTTTCCAGAGCACTTCAC

Reverse CTCCTCGTCCTCATCGTAGC

HIF- $1 \alpha$

Forward

TGGATGGCTTTGTTATGGTG

Reverse TGGTCACATGGATGGGTAAA

$\beta$-actin

Forward

TGTATGCCTCTGGTCGTACC

Reverse

HK-2, hexokinase 2; GPI, glucose-6-phosphateisomerase; PFKL, liver phosphofructokinase; G6PD, glucose 6-phosphate dehydrogenase; PDHB, pyruvate dehydrogenase $\beta$; LDHA, lactate dehydrogenase A; CS, citrate synthase; $\mathrm{ACO} 2$, aconitase 2; IDH2, isocitrate dehydrogenase 2; MDH2, malate dehydrogenase 2; GYS, glycogen synthase; HIF-1 $\alpha$, hypoxia-inducible factor $1 \alpha$.

determined using the Bradford Protein Assay kit (Beyotime Institute of Biotechnology). The proteins samples (30-50 $\mu \mathrm{g}$ ) were separated by $12 \% \mathrm{w} / \mathrm{v}$ SDS-polyacrylamide gel electropho- 
A

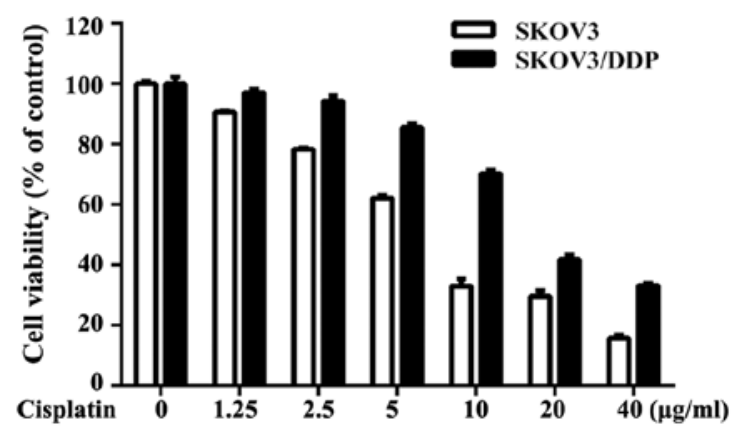

B

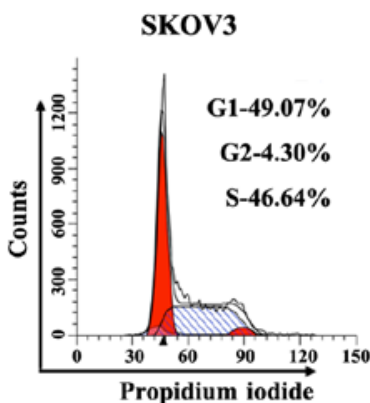

Propidium iodide

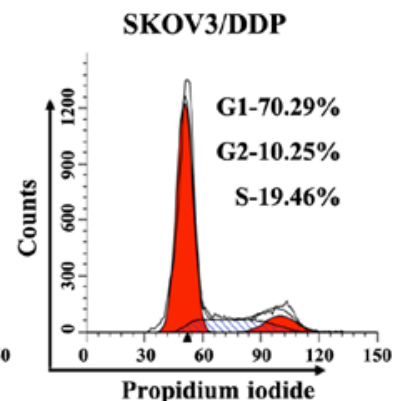

$\mathrm{C}$
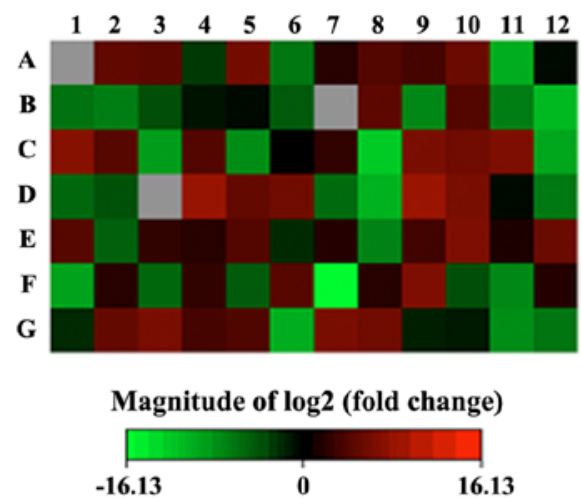

\begin{tabular}{|l|l|l|l|l|l|c|c|c|c|c|c|c|}
\hline & \multicolumn{1}{|c|}{1} & \multicolumn{1}{|c|}{2} & 3 & 4 & 5 & 6 & 7 & 8 & 9 & 10 & 11 & 12 \\
\hline A & ACLY & ACO1 & ACO2 & AGL & ALDOA & ALDOB & ALDOC & BPGM & CS & DLAT & DLD & DLST \\
\hline B & EBO1 & ENO2 & ENO3 & FBP1 & FBP2 & FH & G6PC & G6PC3 & G6PD & GALM & GBE1 & GCK \\
\hline C & GPI & GSK3A & GSK3B & GYS1 & GYS2 & H6PD & HK2 & HK3 & IDH1 & IDH2 & IDH3A & IDH3B \\
\hline D & IDH3G & MDH1 & MDH1B & MDH2 & OGDH & PC & PCK1 & PCK2 & PDHA1 & PDHB & PDK1 & PDK2 \\
\hline E & PDK3 & PDK4 & PDP2 & PDPR & PFKL & PGAM2 & PGK1 & PGK2 & PGLS & PGM1 & PGM2 & PGM3 \\
\hline F & PHKA1 & PHKB & PHKG1 & PHKG2 & PKLR & PRPS1 & PRPS1L1 & PRPS2 & PYGL & PYGM & RBKS & RPE \\
\hline G & RPIA & SDHA & SDHB & SDHC & SDHD & SUCLA2 & SUCLG1 & SUCLG2 & TALDO1 & TKT & TPI1 & UGP2 \\
\hline
\end{tabular}

Figure 1. Glucose metabolism is altered in cisplatin-resistant cells. (A) The cells were subjected to various doses of cisplatin for 24 h prior to being evaluated by MTT assay. Data are presented as the mean \pm standard deviation, $n=3$. (B) Flow cytometric analysis of untreated SKOV3 or SKOV3/DDP cells. The percentage of cells in the G0/G1, S, or G2/M phases of the cell cycle was indicated. (C) The expression of glucose metabolism-related genes (84 genes) was evaluated in cells using a human glucose metabolism polymerase chain reaction array. The changes in gene expression are indicated in the heat map. Red indicates upregulation (SKOV3/DDP vs. SKOV3), and green indicates downregulation. The names and positions of the genes name are listed in the table. DDP, cisplatin.

resis and transferred to polyvinylidene difluoride membranes. Then, the membranes were blocked with $5 \%$ (w/v) skim milk in PBST buffer [100 mM NaCl, $10 \mathrm{mM}$ Tris- $\mathrm{HCl}(\mathrm{pH} 7.6)$ and $0.1 \%(\mathrm{v} / \mathrm{v})$ Tween-20] for $1 \mathrm{~h}$ at room temperature, and incubated overnight at $4^{\circ} \mathrm{C}$ with the primary antibody (anti-HK2, 1:1,000 dilution; anti-Bcl-2, 1:1,000 dilution; anti-G6PD, 1:1,000 dilution; anti- $\beta$-actin, 1:1,000 dilution; anti-PDHB, 1:1,000 dilution; anti-HIF-1 $\alpha, 1: 200$ dilution and anti-Glut1, 1:200 dilution). The following day, the membranes were washed with PBST and incubated with secondary antibodies (1:2,000 dilution). The membranes were detected using the ECL reagents and captured using the Syngene Bio Imager (Synoptics Ltd., Cambridge, UK).

Biochemical measurements. A total of $1 \times 10^{6}$ SKOV3 or SKOV3/ DDP cells were seeded in a $25 \mathrm{~cm}^{2}$-cell culture flask. Following overnight incubation at $37^{\circ} \mathrm{C}$, the complete medium was changed to fresh medium. After $24 \mathrm{~h}, 5 \times 10^{6}$ cells were collected followed by protein extraction by sonication and quantifica- tion using the Bradford Protein Assay kit. Then, the cells were subjected to analysis with the NADP ${ }^{+}$NADPH Quantification kit (BioVision, Inc., Milpitas, CA, USA) to determine NADPH levels and NADPH/NADP ${ }^{+}$ratios. The cellular glutathione (GSH) and glutathione disulfide (GSSG) levels and GSH/GSSG ratio were determined using commercial colorimetric kits (Jiancheng Bio) (26). The glucose 6-phosphate dehydrogenase (G6PD) activity was determined using commercial colorimetric kits (BioVision Inc.). The absorbance was determined using a microplate reader (BioTek Instruments, Inc.).

Flow cytometric analysis of apoptosis. A total of $5 \times 10^{5}$ cells were plated in 6-well plates and incubated overnight at $37^{\circ} \mathrm{C}$. Following exposure to ABT737 and/or cisplatin at $37^{\circ} \mathrm{C}$ for $24 \mathrm{~h}$, the cells were collected. The induction of apoptosis in these cells was determined using Annexin V-FITC (Annexin V Apoptosis Detection Kit II, BD Biosciences, San Diego, CA, USA). The cells were analyzed using a flow cytometer (BD Biosciences). 
Table II. Functional grouping of gene expression.

\begin{tabular}{|c|c|c|}
\hline Functional gene grouping & Upregulated & Downregulated \\
\hline \multicolumn{3}{|l|}{ Glucose metabolism } \\
\hline Glycolysis & $\begin{array}{l}\text { ALDOA, BPGM, GALM, GPI, } \\
\text { HK2, PFKL, PGM1, PGM3 }\end{array}$ & $\begin{array}{l}\text { ALDOB, ENO1, ENO2, ENO3, } \\
\text { GCK, HK3, PGK2, PKLR, TPI1 }\end{array}$ \\
\hline Gluconeogenesis & G6PC3, PC, & G6PC, PCK1, PCK2 \\
\hline Regulation & PDK3, PDP2 & PDK2, PDK4 \\
\hline TCA cycle & $\begin{array}{l}\text { ACO1, ACO2, CS, DLAT, IDH1, IDH2, IDH3A, } \\
\text { MDH2, OGDH, PDHA1, PDHB, SDHA, SDHB, } \\
\text { SDHC, SDHD, SUCLG1, SUCLG2 }\end{array}$ & $\begin{array}{l}\text { ACLY, DLD, FH, IDH3B, IDH3G, } \\
\text { MDH1, MDH1B, SUCLA } 2\end{array}$ \\
\hline PPP & PGLS & PRPS1L1, RBKS, RPIA \\
\hline \multicolumn{3}{|l|}{ Glycogen metabolism } \\
\hline Synthesis & GYS1 & UGP2, GYS2, GBE1 \\
\hline Degradation & PYGL & AGL, PYGM \\
\hline Regulation & PHKG2, GSK3A & PHKA1, PHKG1, GSK3B \\
\hline \multicolumn{3}{|c|}{$\begin{array}{l}\text { ACLY, ATP citrate lyase; ACO, aconitase; AGL, amylo-1, 6-glucosidase, 4- } \alpha \text {-glucanotransferase; ALDOA, aldolase, fructose-bisphos- } \\
\text { phate A; ALDOB, aldolase, fructose-bisphosphate B; BPGM, bisphosphoglycerate mutase; CS, cistrate synthase; DLAT, dihydrolipoamide } \\
\text { S-acetyltransferase; DLD, dihydrolipoamide dehydrogenase; ENO, enolase; FH, fumarate hydratase; GALM, galactose mutarotase; GBE1, } \\
\text { 1,4- } \alpha \text {-glucan branching enzyme } 1 \text {; GCK, glucokinase; GPI, glucose-6-phosphate isomerase; GSK3A, glycogen synthase kinase } 3 \alpha \text {; GSK3B, } \\
\text { glycogen synthase kinase } 3 \beta ; \text { GYS, glycogen synthase; G6PC3, glucose-6-phosphatase catalytic subunit 3; HK2, hexokinase 2; IDH, isocitrate } \\
\text { dehydrogenase; MDH, malate dehydrogenase; OGDH, oxoglutarate dehydrogenase; PC, pyruvate carboxylase; PCK1, phosphoenolpyruvate } \\
\text { carboxykinase 1; PDHA1, pyruvate dehydrogenase E1 } \alpha 1 \text { subunit; PDHB, pyruvate dehydrogenase E1 } \beta \text { subunit; PDK3, pyruvate dehydroge- } \\
\text { nase kinase 3; PDP2, pyruvate dehyrogenase phosphatase catalytic subunit 2; PFKL, phosphohexokinase; PGK2, phosphoglycerate kinase 2; } \\
\text { PHKG2, phosphorylase kinase catalytic subunit } \gamma 2 \text {; PLS, 6-phosphogluconolactonase; PGM, phosphoglucomutase; PHKG1, phosphorylase } \\
\text { kinase catalytic subunit } \gamma 1 \text {; PKLR, pyruvate kinase L/R; PPP, pentose phosphate pathway; PRPS1L1, phosphoribosyl pyrophosphate syn- } \\
\text { thetase 1-like 1; PYGL, glycogen phosphorylase L; PYGM, glycogen phosphorylase, muscle associated; RBKS, ribokinase; RPIA, ribose } \\
\text { 5-phosphate isomerase A; SDH, succinate dehydrogenase complex flavoprotein; SUCLG, succinate-CoA ligase; TCA, tricarboxylic acid; } \\
\text { TPI1, triosephosphate isomerase 1; UGP2, UDP-glucose pyrophosphorylase } 2 \text {. }\end{array}$} \\
\hline
\end{tabular}

Assessment of intracellular ROS level and intramitochondrial superoxide anion. The intracellular reactive oxygen species (ROS) and intramitochondrial superoxide anion $\left(\mathrm{O}_{2}^{-}\right)$were also determined using DCFH-DA and MitoSOX Red, respectively. A total of $5 \times 10^{5}$ cells were plated in 6 -well plates and incubated overnight at $37^{\circ} \mathrm{C}$. Following treatment as indicated in the figure legends, the cells were washed with PBS. DCFH-DA $(10 \mu \mathrm{M})$ or MitoSOX Red $(5 \mu \mathrm{M})$ was added to the cells and cultured at $37^{\circ} \mathrm{C}$ and $5 \% \mathrm{CO}_{2}$ for $20 \mathrm{~min}$. Then, the cells were collected. The fluorescence of the stained cells was detected using a flow cytometer (BD Biosciences).

Live/dead cell viability assay. Cell death was detected using Calcein-AM/PI Double Stain Kit (Shanghai Yeasen Biotechnology Co., Ltd, Shanghai, China). Briefly, following treatment, the SKOV3 or SKOV3/DDP cells were cultured with $2 \mu \mathrm{M}$ propidium iodide and $4 \mu \mathrm{M}$ calcein acetoxymethyl ester in an incubator at $37^{\circ} \mathrm{C}$ and $5 \% \mathrm{CO}_{2}$ for $30 \mathrm{~min}$. After rinsing with PBS, the viability of the cells was then determined using an IX71 fluorescence microscope. The dead and alive cells represented by bright red or green fluorescence were identified upon excitation at 544 and $485 \mathrm{~nm}$, respectively.

Statistical analyses. The data were analyzed by one-way analysis of variance using SPSS (version 21.0; IBM Corp., Armonk, NY, USA). Tukey's post hoc test was used to determine the significance for all pairwise comparisons of interest.
The data were obtained from three experiments and presented as the mean \pm standard deviation. $\mathrm{P}<0.05$ was considered to indicate a statistically significant difference.

\section{Results}

Glucose metabolism is altered in cisplatin-resistant cells. A pair of isogenic ovarian cancer cell lines that were cisplatinsensitive (SKOV3) or cisplatin-resistant (SKOV3/DDP) was used. SKOV3/DDP, a subline of SKOV3, acquired resistance to cisplatin in vitro (5). As expected, SKOV3/DDP cells exhibited considerable resistance to cisplatin, while SKOV3 cells also exhibited resistance to cisplatin as determined by the MTT assay following exposure to increasing concentrations of cisplatin for $24 \mathrm{~h}$ (Fig. 1A). As shown in Fig. 1B, SKOV3/DDP cells were preferentially enriched for G0/G1 quiescent cells and had a lower proliferation rate. The expression of genes associated with glucose metabolism was assessed by RT2 Human Glucose Metabolism Profiler PCR array. The obtained results indicated the upregulation of glycolysis, the tricarboxylic acid cycle (TCA) cycle and gluconeogenesis in SKOV3/ DDP cells (Fig. 1C and Table II).

Cisplatin-resistant cells exhibit a higher glucose demand. Further study suggested that glucose metabolism in SKOV3/DDP cells may be altered compared with SKOV3 cells with increased glucose uptake and consumption 
A

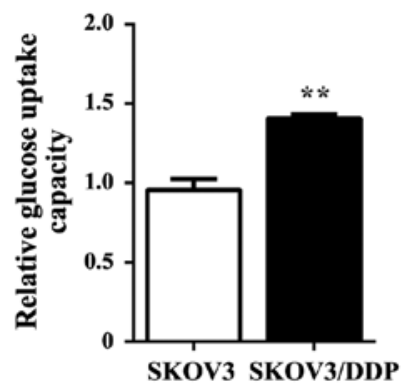

B

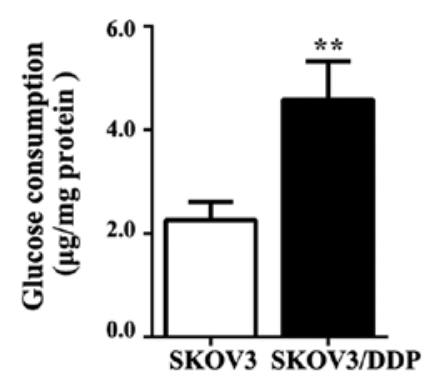

C

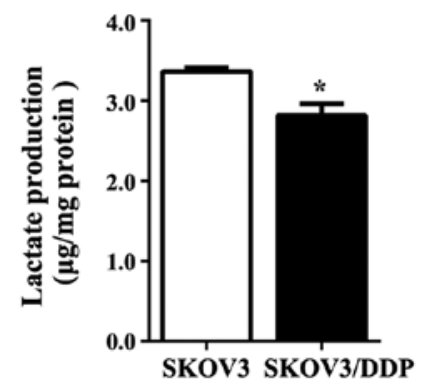

D

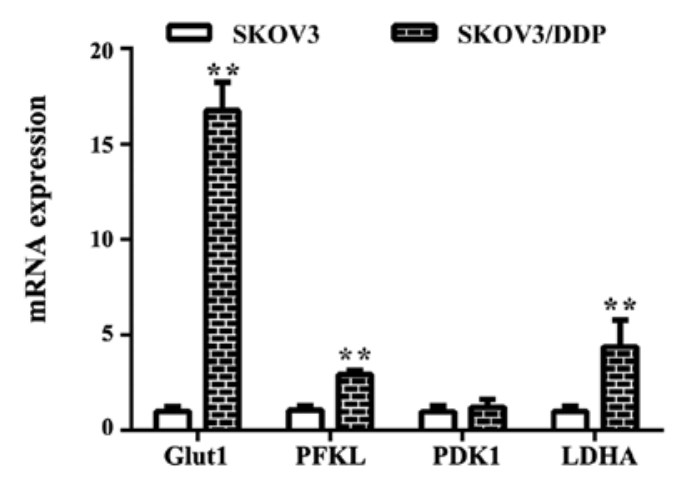

$\mathbf{E}$

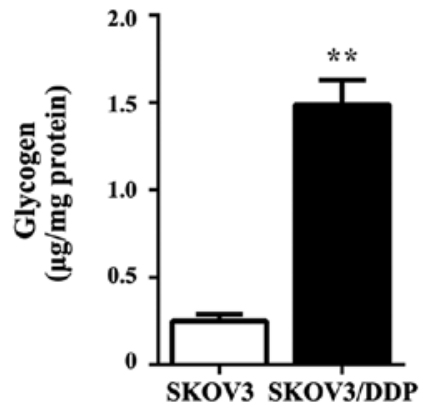

$\mathbf{F}$

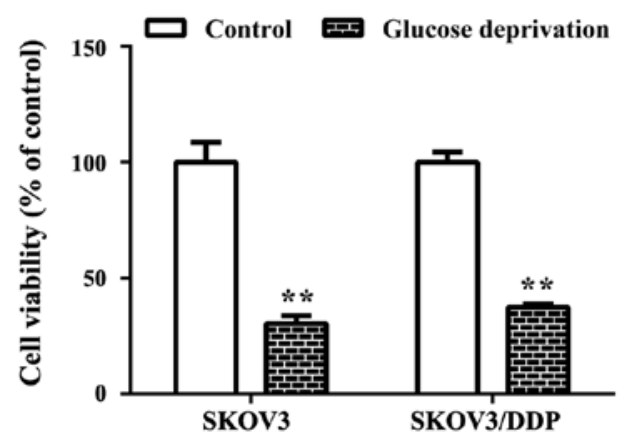

G

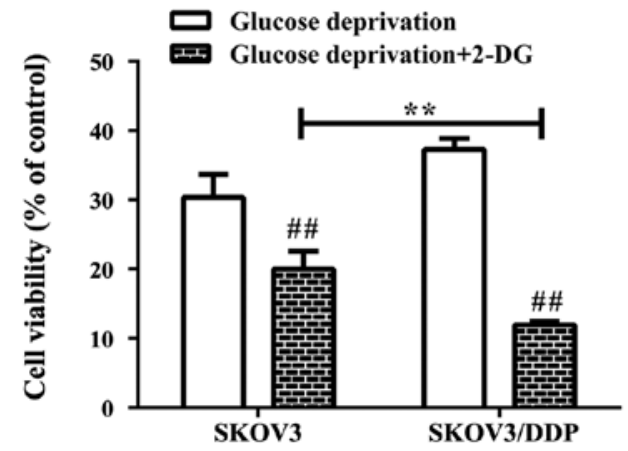

Figure 2. Cisplatin-resistant cells exhibit a higher demand for glucose. (A) The glucose uptake of SKOV3 or SKOV3/DDP cells was determined using the glucose analogue 2-NBDG. ${ }^{* *} \mathrm{P}<0.01$ vs. SKOV3 cells. (B) Glucose consumption and (C) lactate production were measured in the culture media using glucose and lactate kit and normalized to the protein content. ${ }^{*} \mathrm{P}<0.05,{ }^{* *} \mathrm{P}<0.01$ vs. SKOV3 cells. (D) Expression levels of glycolytic genes were determined using quantitative polymerase chain reaction. The genes were normalized to $\beta$-actin. ${ }^{* *} \mathrm{P}<0.01$ vs. SKOV3 cells. (E) Glycogen levels were determined using a glycogen kit. ${ }^{* *} \mathrm{P}<0.01$ vs. SKOV3 cells. (F) The effects of glucose deprivation on cell viability were determined by MTT assay. The data are presented as the percentage of cell number compared with the control group and as the mean \pm standard deviation $(n=3)$. ${ }^{* *} \mathrm{P}<0.01$ vs. control. (G) The effects of glucose deprivation combine with $10 \mathrm{mM} 2-\mathrm{DG}$ on cell viability in two cell lines. ${ }^{* * *} \mathrm{P}<0.01$ vs. SKOV3 cells. ${ }^{\# \#} \mathrm{P}<0.01$ vs. glucose deprivation group. DDP, cisplatin; PFKL, liver phosphofructokinase; PDK1, pyruvate dehydrogenase kinase 1; LDHA, lactate dehydrogenase A.

(Fig. 2A and B), decreased lactate production (Fig. 2C), and overexpression of the glucose metabolism-associated genes, $P F K L$ and $L D H A$, and the glucose transporter Glut as well as elevated glycogen levels (Fig. 2D). As glycogen is a branched polymer of glucose that acts as an intracellular glucose store, high glycogen levels may render the cells less sensitive to glucose deprivation (Fig. 2E). Notably, SKOV3/DDP cells exhibited reduced sensitivity to glucose deprivation compared with SKOV3 cells (Fig. 2F), while the combined treatment with 2-DG (glycolysis inhibitor) induced significant cell death compared with the glucose deprivation alone group (Fig. 2G).

Cisplatin-resistant cells exhibit an increase in oxygen consumption. Numerous studies have previously demonstrated that the Warburg effect is extremely important to ovarian tumor growth $(27,28)$. An analysis of the extracellular acidification rate (ECAR) indicated that ECAR was significantly lower (Fig. 3A) in SKOV3/DDP cells compared with SKOV 3 cells, indicating a reduction of the Warburg effect in cisplatin-resistant cancer cells. 2-DG, a glycolytic inhibitor, blocks glycolysis by inhibiting hexokinase, which is the key rate-limiting enzyme of glycolysis. The results of the present study suggested that SKOV3/DDP cells were less sensitive to 2-DG compared with SKOV3 cells (Fig. 3B). As the basal rate of glycolysis in SKOV3/DDP cells was lower compared with SKOV3 cells, the metabolic status of SKOV3/DDP cells might involve downregulation of glycolysis and a shift toward OXPHOS. To investigate this hypothesis, the OCR (which is indicative of OXPHOS) in SKOV3 and SKOV3/DDP 
A

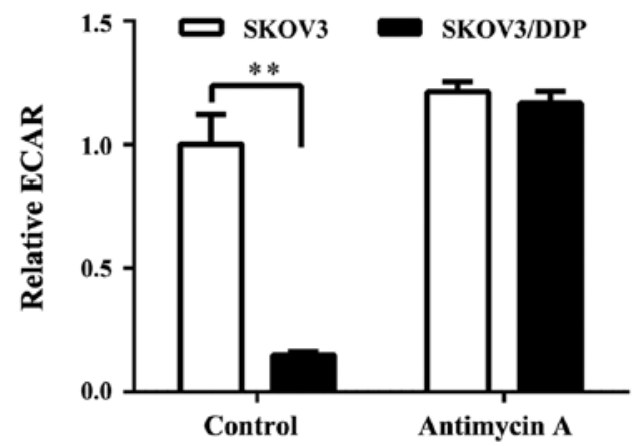

B

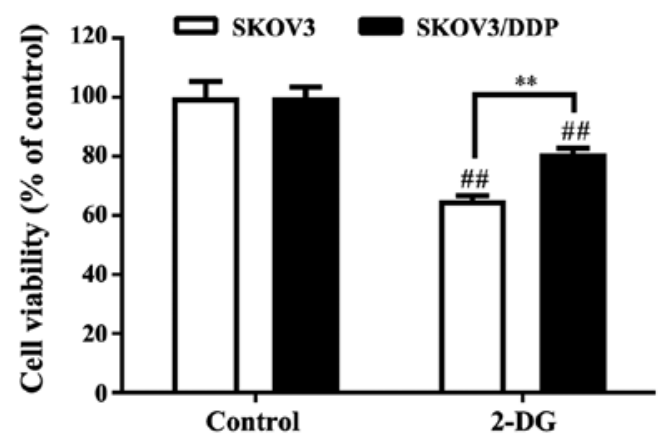

C

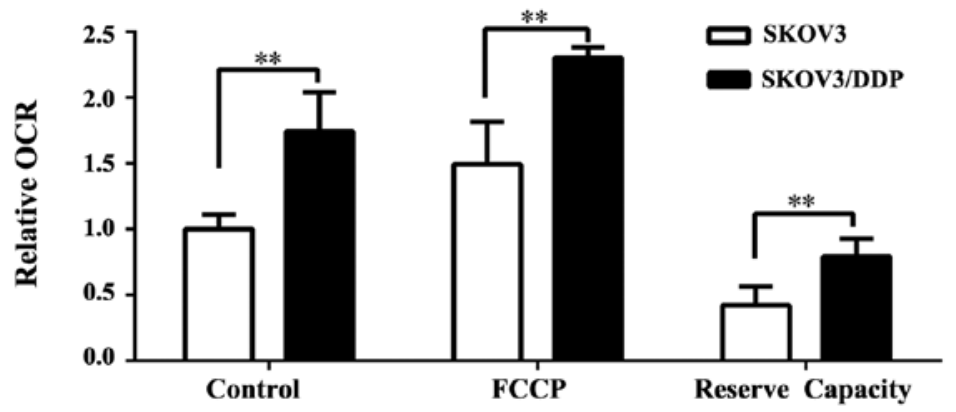

D

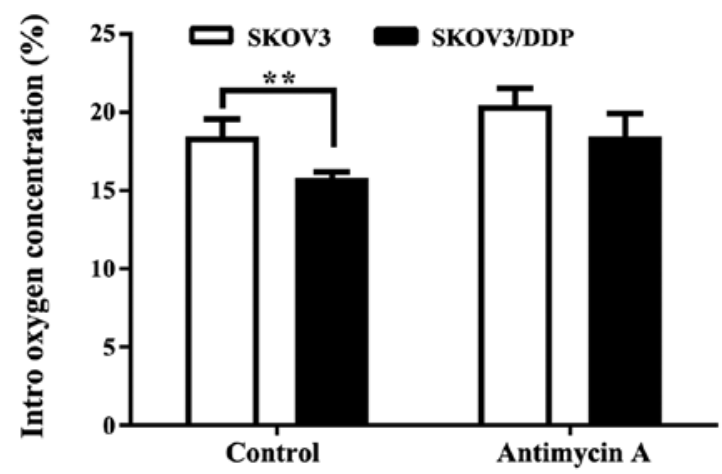

$\mathbf{E}$

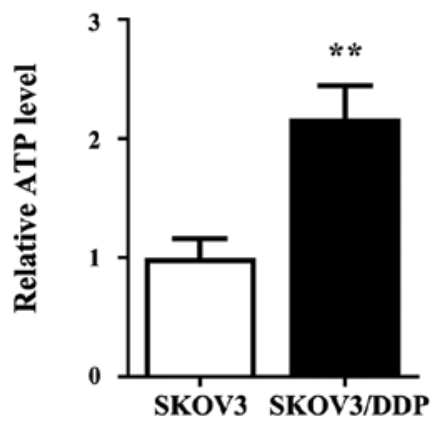

Figure 3. Cisplatin-resistant cells exhibit an increase in oxygen consumption. (A) Extracellular acidification rates were measured in untreated or SKOV3 or SKOV3/DDP cells that were treated with $2.5 \mu \mathrm{M}$ antimycin A. (B) The cells were untreated or treated with $10 \mathrm{mM} 2$-DG for $24 \mathrm{~h}$ prior to being subjected to a MTT assay. ${ }^{\# \#} \mathrm{P}<0.01$ vs. control group. ${ }^{* *} \mathrm{P}<0.01$ vs. SKOV3 cells. (C) The basal and maximal OCRs were determined in DMSO-treated control or in cells that were treated with $2.5 \mu \mathrm{M}$ FCCP. Reserve capacity was calculated by subtracting the basal OCR from the maximum OCR. (D) Intracellular oxygen concentration was determined in the DMSO-treated control or in cells that were exposed to $2.5 \mu \mathrm{M}$ antimycin A. (E) The ATP levels were quantified. ${ }^{* *} \mathrm{P}<0.01$ vs. SKOV3 cells. FCCP, carbonyl cyanide 4-(trifluoromethoxy)phenylhydrazone; OCR, oxygen consumption rate.

cells was measured. As shown in Fig. 3C, SKOV3/DDP cells demonstrated significantly higher OCR, which represented higher oxidative metabolism compared with SKOV3 cells. Consistent with this finding, the intracellular oxygen concentration was lower in SKOV3/DDP cells compared with SKOV3 cells (Fig. 3D). Furthermore, the ATP level was higher in SKOV3/DDP compared with SKOV3 cells (Fig. 3E).

Cisplatin-resistant cells have elevated levels of intramitochondrial superoxide anion $\left(\mathrm{O}_{2}^{-}\right)$and intracellular $\mathrm{ROS}$. As oxidative processes mainly take place in the mitochondria, whether the increased oxygen consumption demonstrated in SKOV3/DDP cells was a result of increased mitochondrial mass was investigated.

Notably, compared with the level in SKOV3 cells, SKOV3/DDP cells exhibited a marked increase in staining with MTG (MitoTracker green) (Fig. 4A). Furthermore,
SKOV3/DDP cells exhibited a marked increase in labeling with the mitochondrial-specific redox probe, MitoSox-Red, suggesting that increased ROS content originated from the mitochondria and that mitochondria were the main source of oxidative metabolism in SKOV3/DDP cells (Fig. 4B). Moreover, the level of intracellular ROS in SKOV3/DDP cells was markedly increased in comparison to SKOV3 cells (Fig. 4C). Given their increased oxygen consumption, SKOV3/ DDP cells exhibit a more pro-oxidant state.

To investigate whether the inhibition of mitochondrial respiration was able to lead to oxidative stress and induce the death of SKOV3/DDP cells, the complex I inhibitor, rotenone, was used. It was found that the intracellular levels of ROS that were detected by fluorescence of the redox dye DCFH-DA, decreased (Fig. 4D). By contrast, the number of dead cells, as detected by bright red fluorescence in the live/dead cell viability assay, was markedly increased upon treatment with 
A
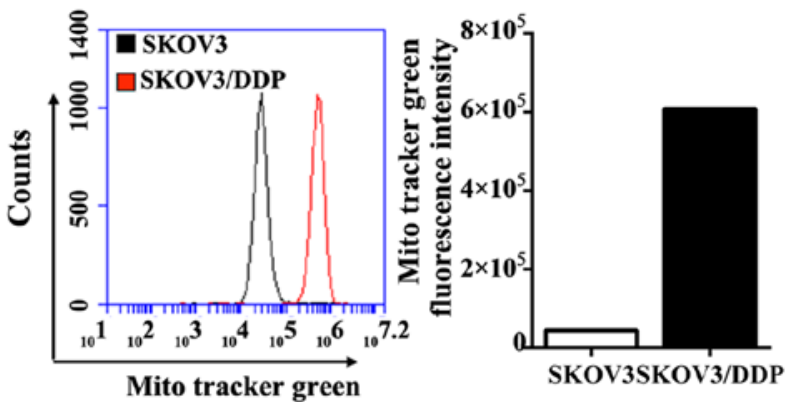

$\mathrm{C}$
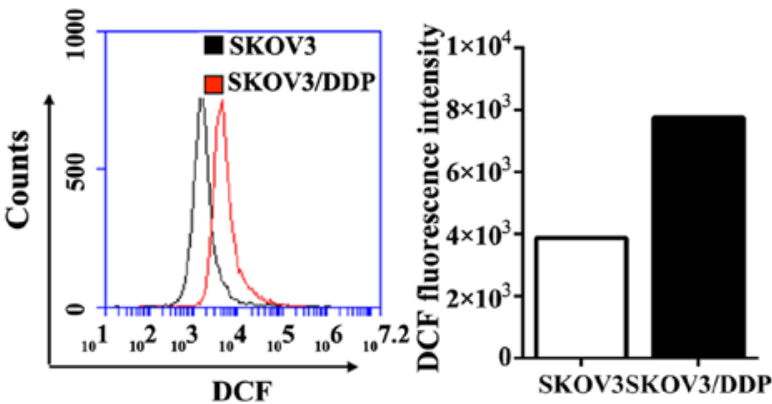

E

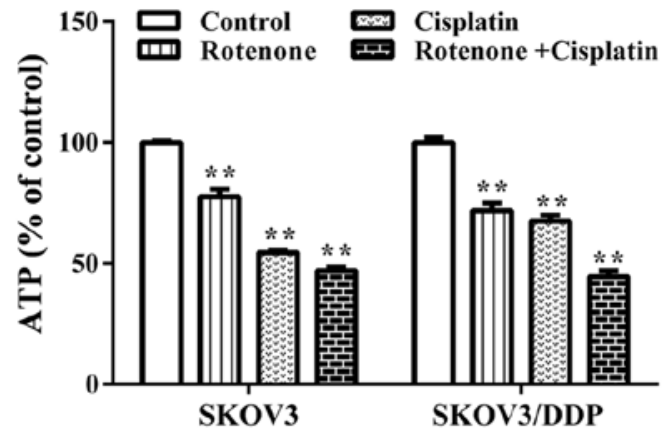

B
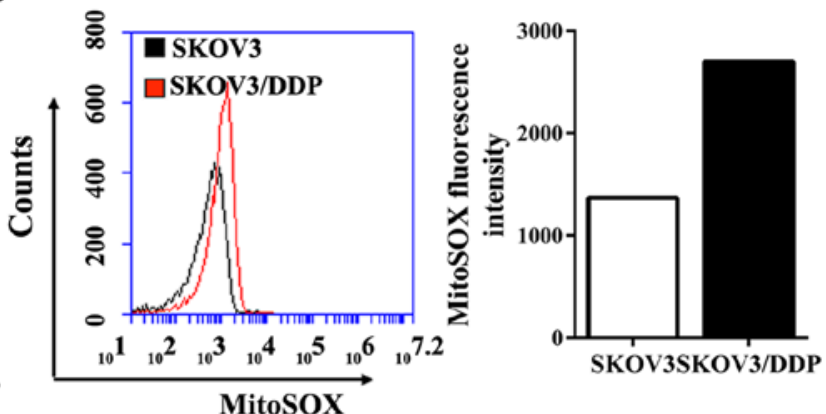

D
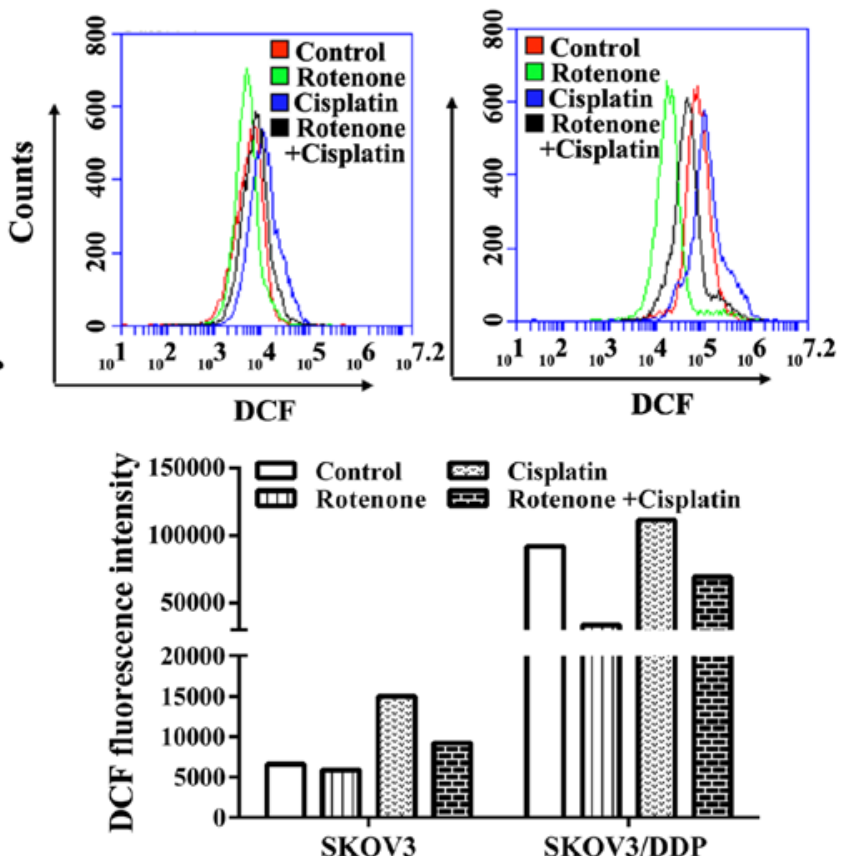

$\mathrm{F}$
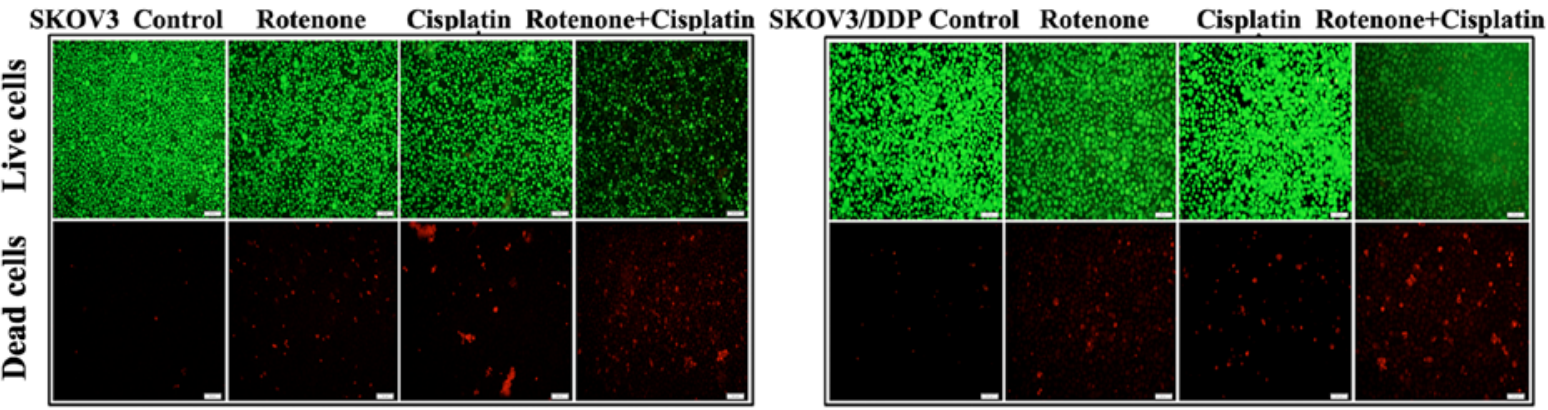

Figure 4. Cisplatin-resistant cells have elevated levels of intramitochondrial superoxide anion $\left(\mathrm{O}_{2}{ }^{-}\right)$and intracellular ROS. (A) Mitochondrial mass was detected using MitoTracker Green staining. (B) The levels of intramitochondrial $\mathrm{O}_{2}{ }^{-}$were determined using MitoSox Red fluorescence. (C) The levels of intracellular ROS were determined using the oxidant-sensitive dye DCFH-DA. Following exposure to $1 \mu \mathrm{M}$ rotenone with or without $6 \mu \mathrm{g} / \mathrm{ml}$ cisplatin for $24 \mathrm{~h}$, the cells were subjected to assays to determine the changes in the intracellular ROS (D) and ATP (E) levels or to determine the viability of cells using a live/ dead cell viability assay (F) under a fluorescence microscope (scale bars, $200 \mu \mathrm{m}$ ). ${ }^{* *} \mathrm{P}<0.01$. ROS, reactive oxygen species.

cisplatin plus rotenone compared with treatment with cisplatin alone (Fig. 4F). Therefore, it was hypothesized that the marked cell death induced by rotenone may be associated with energy depletion. It was found that the treatment with rotenone and/or cisplatin caused a marked reduction in the ATP level in SKOV3/DDP cells (Fig. 4E). Notably, the present study demonstrated that compared with SKOV3 cells, SKOV3/DDP cells might rely more on the respiration of mitochondria rather than the Warburg effect to meet their energy demands.
Redox homeostasis in SKOV3/DDP cells is maintained intrinsically by pairing OXPHOS with pentose phosphate pathway $(P P P)$. The level of the antioxidant molecule, NADPH, which can be used to scavenge ROS (29), increased in SKOV3/DDP cells compared with SKOV3 cells (Fig. 5A). The ratio of NADPH to NADP ${ }^{+}$in SKOV3/DDP cells also increased relative to the ratio in SKOV3 cells (Fig. 5B). GSH, an important redox buffer in cancer cells, has been considered to participate in sustaining cisplatin resistance (30). In SKOV3/DDP cells, 
A

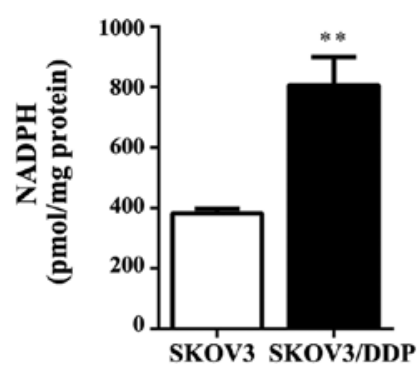

D

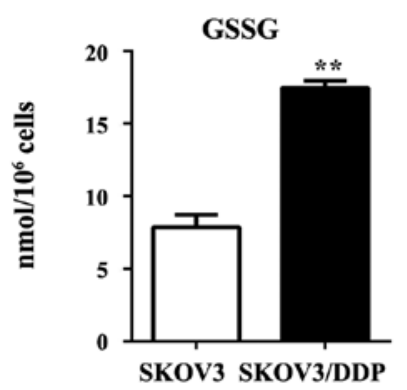

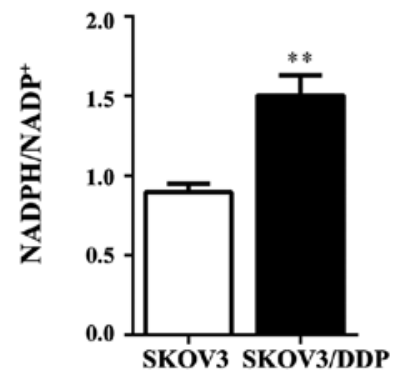

E

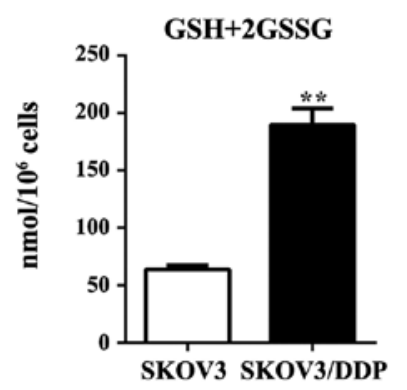

C

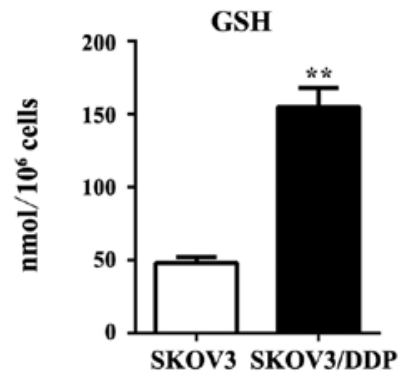

G

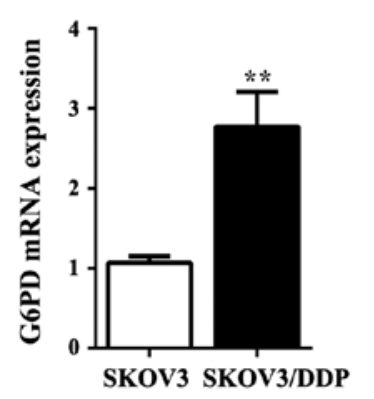

H

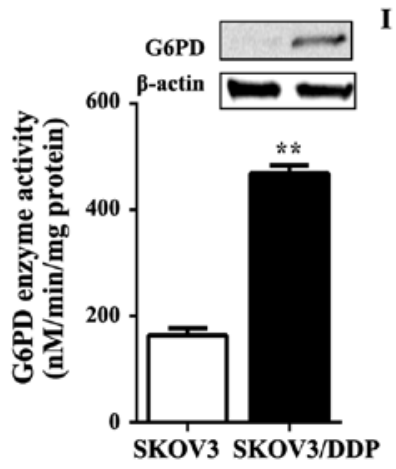

I

F

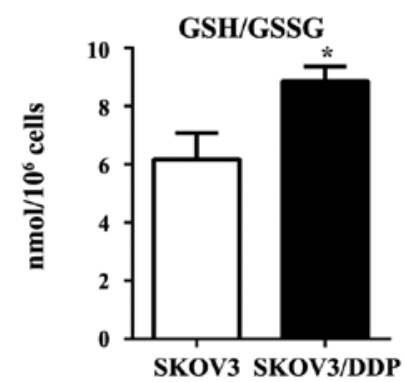

Figure 5. Redox homeostasis in SKOV3/DDP cells is maintained intrinsically by pairing oxidative phosphorylation with pentose phosphate pathway. (A) Cellular NADPH content and (B) NADPH/NADP ratio, (C) GSH and (D) GSSG contents, (E) total GSH (GSH plus GSSG) level and (F) GSH/GSSG ratio determined using enzymatic assays. (G) The expression level G6PD gene was detected using reverse transcription-quantitative polymerase chain reaction. (H) G6PD protein expression level was determined using western blotting, and the enzymatic activity was analyzed using a G6PD assay kit. The data are representative of three experiments. (I) Cell viability of SKOV3 or SKOV3/DDP cells was determined using a MTT assay in the presence of G6PD inhibitors $\left(20 \mu \mathrm{M}\right.$ 6-AN or $250 \mu \mathrm{M}$ DHEA) with or without cisplatin for $24 \mathrm{~h} .{ }^{*} \mathrm{P}<0.05,{ }^{* *} \mathrm{P}<0.01$ vs. SKOV3 cells. ${ }^{\# *} \mathrm{P}<0.01$ vs. cisplatin treated group. DDP, cisplatin; G6PD, glucose-6-phosphate dehydrogenase; GSH, glutathione; GSSG, glutathione disulfide.

GSH and GSSG contents, total GSH (GSH plus GSSG), and the GSH to GSSG ratio were significantly higher than those in SKOV3 cells (Fig. 5C-F). Moreover, the oxidative PPP branch is a major source of NADPH for cells, and substantial evidence has demonstrated that cancer cells mainly rely on the oxidative PPP branch to maintain redox homeostasis (31). Therefore, the authors hypothesized that SKOV3/DDP cells might exploit the PPP pathway to increase GSH biosynthesis to compensate for the increased ROS generated by OXPHOS. G6PD is a major rate-limiting enzyme for the activity of PPP. Notably, the gene and protein expression of G6PD (Fig. 5G) as well as its activity (Fig. 5H) were increased in SKOV3/DDP cells compared with the levels in SKOV3 cells.

To better understand the role of PPP in cisplatin resistance, the cells were treated with the competitive G6PD inhibitor 6-AN (6-aminonicotinamide) (32) or the uncompetitive G6PD inhibitor DHEA (dehydroepiandrosterone) (33) with or without $6 \mu \mathrm{g} / \mathrm{ml}$ cisplatin. In SKOV3 cells, the treatment of 6 -AN or DHEA together with cisplatin for $24 \mathrm{~h}$ induced no significant effect on cell viability compared with the cisplatin alone group (Fig. 5I). By contrast, in SKOV3/DDP cells, treatment with 6-AN or DHEA together with cisplatin significantly reduced cell viability compared with the cisplatin alone group (Fig. 5I). These results suggested that SKOV3/DDP cells exploit oxidative PPP as a resistance mechanism. These results also demonstrated that SKOV3/DDP cells utilize the oxidative PPP branch as a mechanism of resistance to cisplatin by contributing to redox buffering.

ABT737 sensitizes ovarian cancer cells to cisplatin treatment. SKOV3/DDP cells exhibit an overexpression of the Bcl-2 protein, which might render them more resistant to cisplatin (Fig. 6A and B). The increased expression of Bcl-2 in SKOV3/DDP cells is potentially important because $\mathrm{Bcl}-2$ not only participates in the apoptotic pathway but also is involved in mitochondrial metabolism (34). To examine the mechanisms of Bcl-2 in cisplatin resistance, the cell survival rate was examined via MTT assays following exposure to various doses of the $\mathrm{Bcl}-2$ inhibitor, 
$\mathbf{A}$

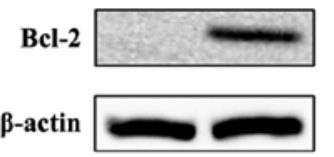

SKOV3 SKOV3/DDP
B

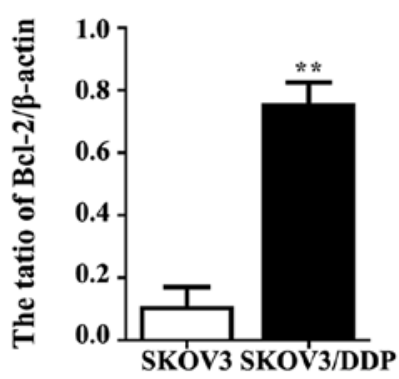

C

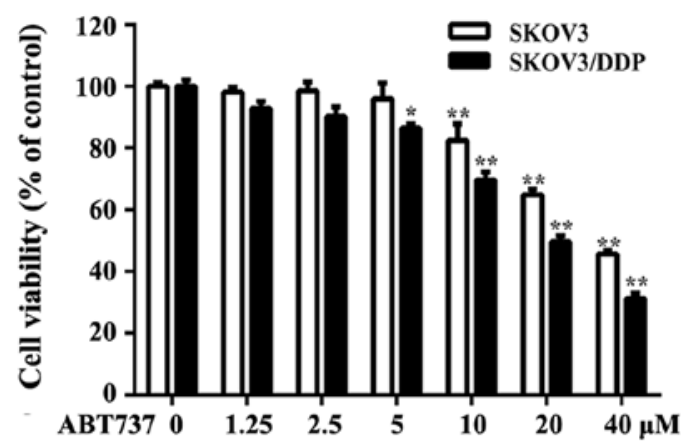

$\mathbf{E}$

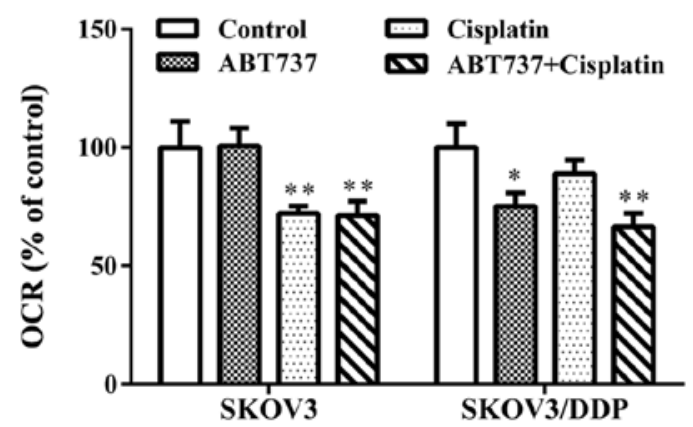

$\mathbf{F}$

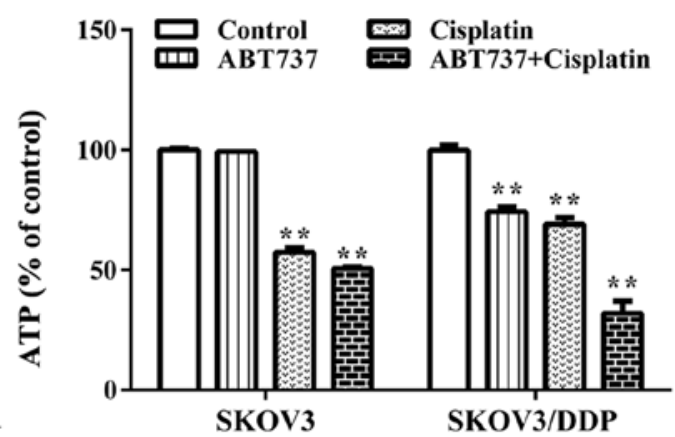

H

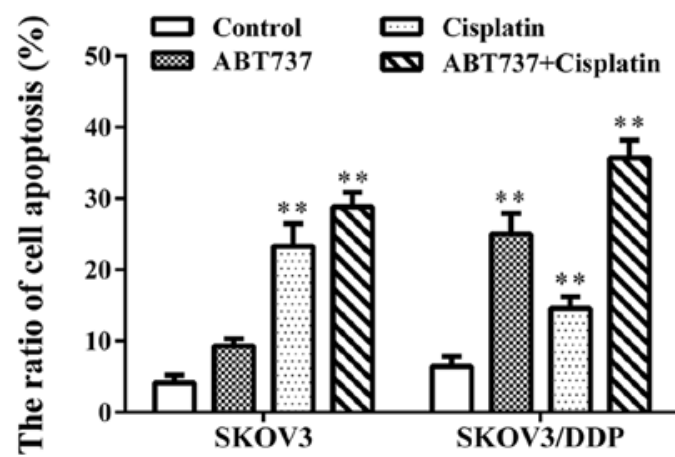

Figure 6. ABT737 sensitizes ovarian cancer cells to cisplatin treatment. (A) The expression level of Bcl-2 protein in SKOV3 or SKOV3/DDP cells was determined using western blot analysis. (B) Quantification of Bcl-2 protein level. The data are representative of three experiments. ${ }^{* *} \mathrm{P}<0.01 \mathrm{vs}$. SKOV3 cells. (C) Following exposure to various doses of ABT737 for $24 \mathrm{~h}$, cell viability was detected using a MTT assay. The data are representative of three experiments. ${ }^{*} \mathrm{P}<0.05,{ }^{* * *} \mathrm{P}<0.01$ vs. control group. (D) The expression of glucose metabolism-associated genes was determined using reverse transcription-quantitative polymerase chain reaction in the presence of ABT737 $(10 \mu \mathrm{M})$ with or without cisplatin $(6 \mu \mathrm{g} / \mathrm{ml})$ for $8 \mathrm{~h}$. The (E) oxygen consumption rates and (F) cellular ATP level were determined following exposure to ABT737 $(10 \mu \mathrm{M})$ with or without cisplatin $(6 \mu \mathrm{g} / \mathrm{ml})$ for $24 \mathrm{~h}$. (G) Cell apoptosis was assessed by staining with Annexin V-FITC and PI, and analyzed by a BD cell analyzer. (H) The quantification of apoptosis in SKOV3 and SKOV3/DDP cells exposed to different treatment for $24 \mathrm{~h}$. Data are presented as the means \pm standard deviation, $\mathrm{n}=3{ }^{*} \mathrm{P}<0.05,{ }^{* *} \mathrm{P}<0.01$ vs. control group.

ABT737, for $24 \mathrm{~h}$. SKOV3/DDP cells were more sensitive to ABT737 than SKOV3 cells. Based on these MTT results, we treated both cell lines with $10 \mu \mathrm{M}$ ABT737 (Fig. 6C). The effects of ABT737 on glucose metabolism-associated genes and OCR were analyzed in the two cell lines to clarify whether ABT737 affects glucose metabolism before exhibiting notable cytotoxicity, such as by inducing apoptosis. Treatment of the cells ABT737 with or without cisplatin was able to induce a significant decrease in the expression of glucose metabolism-associated genes and a decrease in OCR in SKOV3/DDP cells compared with the control group (Fig. 6D and E), but it had no marked effect on either the expression of glucose metabolism-associated genes or 
A

B
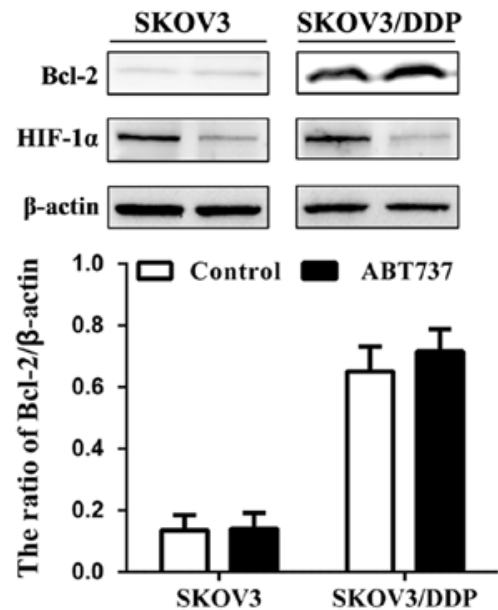

$\mathrm{C}$

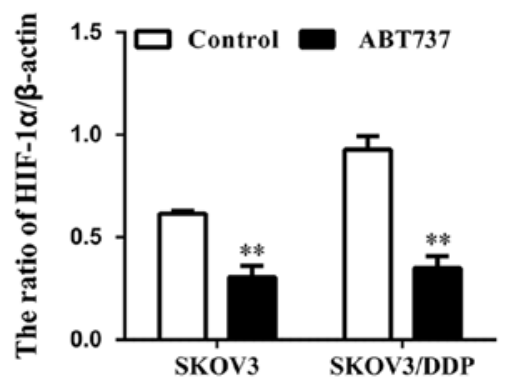

E

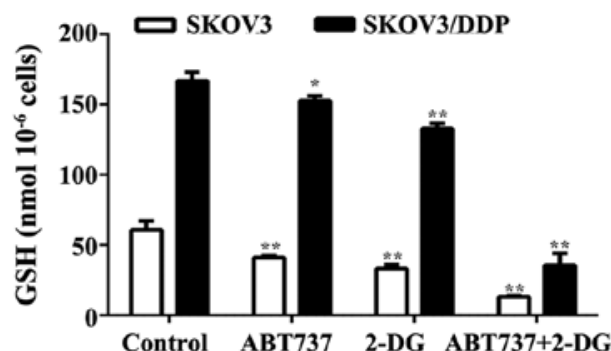

D

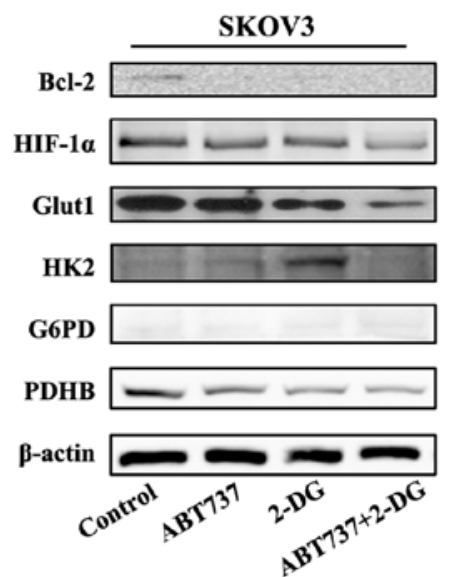

F
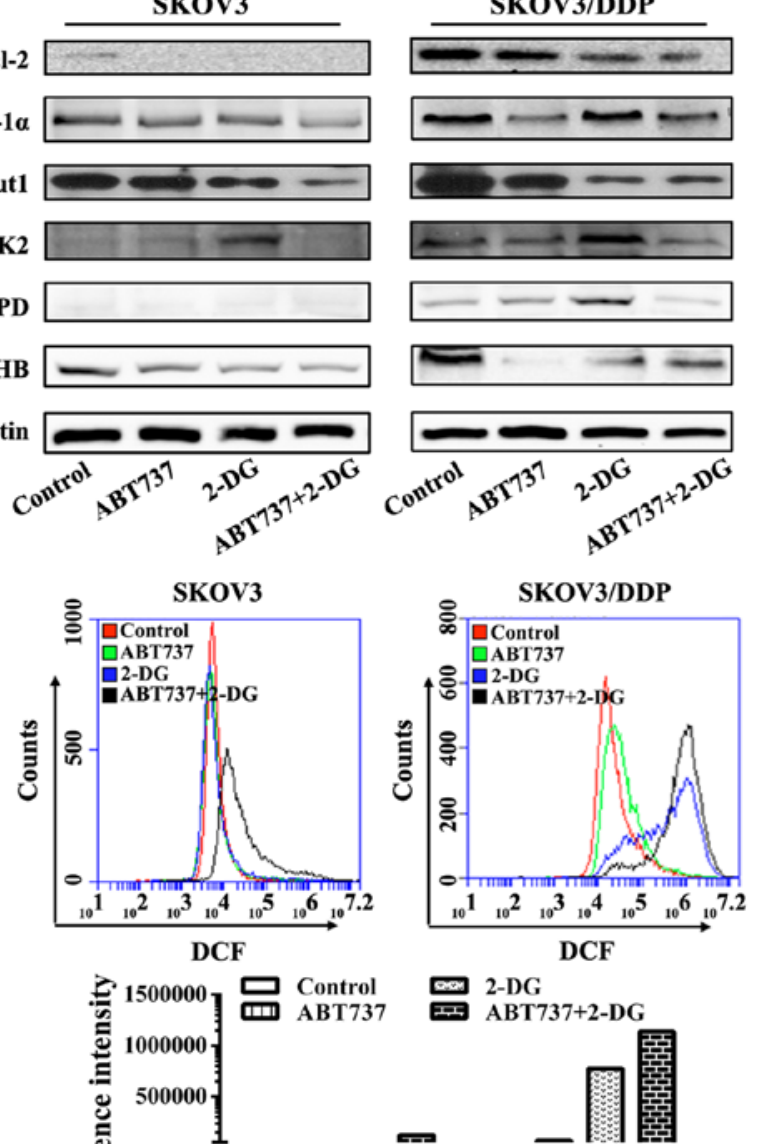

2-DG

田 ABT737+2-DG
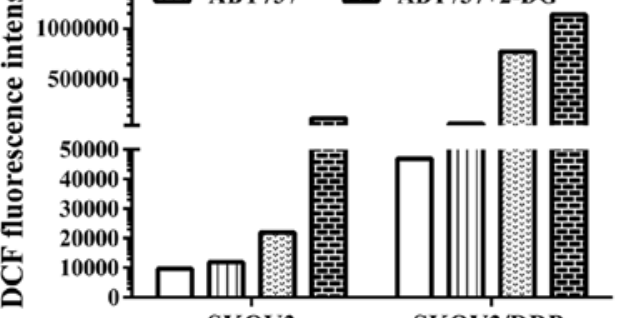

SKOV3

SKOV3/DDP

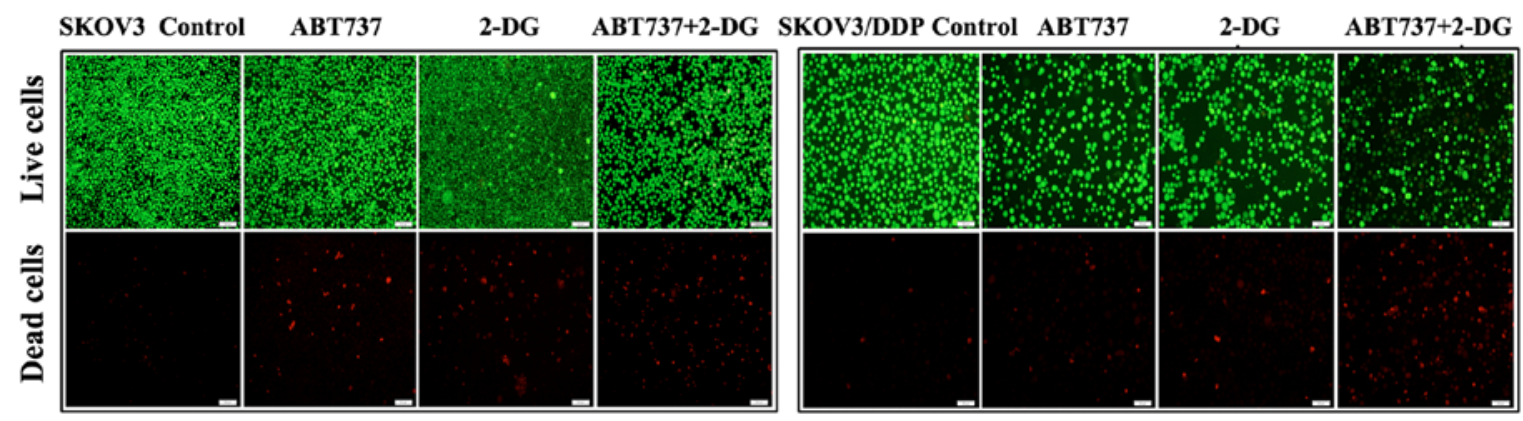

Figure 7. Combination of ABT737 and 2-DG significantly induces cell death by disrupting glucose metabolism. (A) The expression levels of Bcl-2 and HIF-10 protein were analyzed by western blot analysis following exposure to $10 \mu \mathrm{M}$ ABT737 for $24 \mathrm{~h}$. (B) Quantification of the protein levels of Bcl-2. The data are representative of three experiments. (C) Quantification of the protein levels of HIF-1 $\alpha$. The data are representative of three experiments. (D) The expression levels of glucose metabolism-associated proteins were detected using western blot analysis following exposure to ABT737 (10 $\mu \mathrm{M})$ and/or glycolysis inhibitor 2-DG (10 mM) for $24 \mathrm{~h} .{ }^{*} \mathrm{P}<0.05,{ }^{* *} \mathrm{P}<0.01$ vs. control group. (E) GSH levels and (F) reactive oxygen species level in SKOV3 and SKOV3/DDP cells were determined by GSH assay kit or DCFH-DA dye in the presence of ABT737 $(10 \mu \mathrm{M})$ and/or glycolysis inhibitor 2-DG (10 mM) for $24 \mathrm{~h}$. (G) Following exposure to ABT737 $(10 \mu \mathrm{M})$ and/or glycolysis inhibitor 2-DG $(10 \mathrm{mM})$ for $24 \mathrm{~h}$, the cells were subjected to test the viability of cells using live/dead cell viability assay under fluorescence microscopy (scale bars, $200 \mu \mathrm{m}$ ). Bcl-2, B-cell lymphoma 2; GSH, glutathione; HIF-1 $\alpha$, hypoxia-inducible factor $1 \alpha$.

OCR in SKOV3 cells. The ATP level was significantly decreased in SKOV3/DDP cells upon treatment with cisplatin plus ABT737 compared with single treatment of cisplatin or ABT737 (Fig. 6F). Annexin V-FITC staining indicated that treatment with cisplatin plus ABT737 induced significant apoptosis in SKOV3/DDP cells compared with other treatment groups (Fig. 6G and H). These findings indicated that ABT737 induced significant cytotoxicity mainly by inhibiting the respiration of mitochondria in SKOV3/ DDP cells and sensitizing the cells to cisplatin.

Combination of ABT737 and 2-DG significantly induces cell death by disrupting glucose metabolism. Notably, the expression of HIF-1 $\alpha$ was inhibited by ABT737 (Fig. 7A-C), suggesting that ABT737 had a direct effect on HIF-1 $\alpha$ that in turn may affect 
glycolysis. Since ABT737 could reduce the respiration of mitochondria in SKOV3/DDP cells, we proposed that the combined treatment of ABT737 and glycolysis inhibitor 2-DG would play an important therapeutic role in SKOV3/DDP cells. To estimate the effect of ABT737 and 2-DG in combination, we examined changes in the expression of enzymes associated with glucose metabolism (Fig. 7D). In SKOV3/DDP cells, among several proteins related to glucose metabolism, Bcl-2, HIF-1 $\alpha$, Glut1, HK2, G6PD, IDH1 and PDHB exhibited marked decreases in expression following this combination treatment compared with those in the other groups. Compared with that in SKOV3 cells, the GSH level in SKOV3/DDP cells was markedly decreased following treatment with ABT737 plus 2-DG compared with that following treatment with either ABT737 alone or 2-DG alone (Fig. 7E), while the intracellular ROS level in SKOV3/DDP cells was increased accordingly (Fig. 7F). Furthermore, we observed a remarkable increase of the death (Fig. 7G) of SKOV3/DDP cells treated with ABT737 and 2-DG compared with that in the other groups. These results indicate that the glycolysis inhibitor 2-DG enhanced the activation of apoptosis induced by ABT737.

\section{Discussion}

Warburg reported that despite the exposure to sufficient oxygen cancer cells mainly depend on increased glycolysis rather than oxidative respiration to meet their energy demands (15). He suggested that this is due to their defective mitochondria. However, it has become increasingly clear that the mitochondria of cancer cells are generally normal and may participate in tumor growth $(35,36)$. Whether cancer cells utilize glycolysis or oxidative phosphorylation to meet their energy demands depends upon various factors, including the type and stage of cancer cells, the proliferation rate of cells and the sequence of activated oncogenes that is directly associated with mitochondria (37-39). Recently, a study has suggested that the main role of aerobic glycolysis is to maintain glycolytic intermediates at high levels to sustain anabolic reactions, which is selected by highly proliferating cancer cells (37). However, slowcycling cells depend more on OXPHOS (40). In the present study, SKOV3/DDP cells had increased mitochondrial mass, oxygen consumption, ATP level and lower intracellular oxygen concentration compared with SKOV3 cells, suggesting a shift in glucose metabolism in cisplatin-resistant SKOV3/DDP cells from aerobic glycolysis to OXPHOS.

Glucose is predominantly used in ovarian cancer cells to generate ATP and maintain the energy and redox balance (41-43). Many studies have identified that drug-resistant cells are great exploiters of glucose (19,44). For example, Catanzaro et al (45) demonstrated that cisplatin-resistant ovarian cancer cells have an increased demand for glucose and higher sensitivity to glucose deprivation. In line with this, the present study indicated that SKOV3/DDP cells had an increased demand for glucose and exhibited increased glucose uptake and consumption and upregulated expression of the glucose transporter Glut1. However, SKOV3/DDP cells were less sensitive to glucose deprivation due to their larger stores of glycogen. Furthermore, SKOV3/DDP cells exhibited remarkable decreases in extracellular lactate and ECAR (indicative of glycolysis), therefore it was suggested that the metabolism of cisplatin-resistant ovarian cancer cells may vary among different cell lines.
In highly proliferating cancer cells, the shift in metabolism to aerobic glycolysis could avoid damage resulting from oxidative stress, whereas this shift may not be so important in slowly proliferating/quiescent drug-resistant cells $(37,46)$. As the endogenous ROS are mainly derived from mitochondrial OXPHOS, oxidative stress is induced by the accumulation of ROS, which is caused by the imbalance between ROS production and elimination (47). The drug-resistant cells may develop sufficient antioxidant mechanisms. The oxidative branch of PPP is the strongest supporter of cellular ROS defense mechanisms among the antioxidant mechanisms (48). G6PD, the rate-limiting enzyme of PPP, catalyzes the generation of the first molecule of NADPH and is relatively overexpressed in primary breast carcinoma and gastric cancer cells $(49,50)$. Furthermore, the acquisition of cisplatin resistance is associated with the upregulation of G6PD, whose increased expression was previously linked to a cisplatin-resistant phenotype (45). In line with this, the data in the present study demonstrated that in SKOV3/DDP cells despite exhibiting a pro-oxidizing state with higher levels of intramitochondrial superoxide anion $\left(\mathrm{O}_{2}^{-}\right)$and intracellular ROS in comparison to SKOV3 cells, the oxidative branch of PPP was elevated with higher NADPH content, and increased G6PD protein expression and enzymatic activity compared with the levels in SKOV3 cells. Furthermore, the combined treatment with the G6PD inhibitors 6-AN or DHEA and cisplatin was more effective compared with treatment with cisplatin alone in SKOV3/DDP cells. This suggested that the redox homeostasis of SKOV3/DDP cells is maintained by pairing ROS generated from OXPHOS and cisplatin toxicity with reductive equivalent NADPH produced by the oxidative branch of PPP.

Apart from their role in the regulation of mitochondrial apoptosis, $\mathrm{Bcl}-2$ proteins are also able to stimulate mitochondrial respiration (51-53). Moreover, it was found that Bcl-2 protein was upregulated in SKOV3/DDP cells compared with the level in SKOV3 cells. To enhance the cisplatin sensitivity of SKOV3/DDP cells, ABT-737 was utilized to inhibit Bcl-2, Bcl-w and Bcl-xL $(54,55)$. In the present study, it was indicated that ABT737 significantly inhibited mitochondrial OXPHOS and the expression of glucose metabolism-associated genes, causing a reduction in ATP content and impairing the survival of SKOV3/DDP cells. Accordingly, the vital function of OXPHOS in metabolic reprogramming and the induction of cisplatin resistance led the authors to examine the effect of rotenone (inhibitor of mitochondrial complex I) on cisplatin resistance. It was also found that rotenone markedly improved the sensitivity of SKOV3/DDP cells to cisplatin. While ABT737 had no significant effect on OXPHOS in SKOV3 cells, it exhibited a weaker effect on cell survival compared with SKOV3/DDP cells. Therefore, it was hypothesized that ABT737 may inhibit viability less effectively in cancer cells with a lower expression of Bcl-2 protein.

As heterogeneous systems, tumors are composed of both highly proliferative cells and slowly proliferating or quiescent cells, including tumor-initiating cells or cancer stem cells (8). Therefore, to obtain a comprehensive understanding of them, their different metabolic phenotypes need to be considered. HIF-1 $\alpha$ initiates the transcription of genes encoding glucose transporters and glycolytic enzymes $(57,58)$ and has been shown 
to be associated with chemoresistance in many preclinical and clinical studies $(58,59)$. Notably, HIF-1 $\alpha$ may be more stable in SKOV3/DDP cells with a lower intracellular oxygen concentration and a higher level of ROS. In turn, glycogen synthesis is induced through HIF-mediated induction of GYS, which is consistent with the elevated glycogen level in SKOV3/DDP cells. Interestingly, ABT737 caused a remarkable decrease in HIF-1 $\alpha$ expression in SKOV3/DDP cells and SKOV3 cells. Owing to HIF-1 $\alpha$ also initiating the transcription of glucose metabolism-associated genes $(59,60)$, it was suggested that Bcl-2 proteins might also be modulators of HIF-1 $\alpha$ and might thereby contribute to many other parts of glucose metabolism apart from OXPHOS. The previous study by the authors demonstrated that the glycolysis inhibitor, 2-DG, was able to enhance apoptosis that was induced by S1 (Bcl-2 inhibitor) via the upregulation of SIRT3 in SKOV3 cells (25). Furthermore, the use of 2-DG also enhanced the sensitivity of SKOV3/DDP cells to ABT737. The combination of ABT737 and 2-DG significantly decreased GSH content, the expression of HIF-1 $\alpha$ and glucose metabolismassociated proteins, while also inducing marked cell death in SKOV3/DDP cells. Therefore, it was hypothesized that the combination of 2-DG with ABT737 may be applied to exploit the metabolic weakness of cisplatin-resistant cells, circumventing treatment resistance and enhancing treatment efficacy in the heterogeneous systems that are tumors.

\section{Acknowledgements}

The present authors would like to thank Xiao Song Wang, Kuo Wang and Yan Liu for technical contributions and also Liwen Bianji, Edanz Group China, for editing the English text of a draft of this manuscript.

\section{Funding}

The present study was supported by the National Nature and Science Foundation of China (grant nos. 81472419, 81672948 and 81501982), the Jilin Provincial Research Foundation for the Development of Science and Technology Projects (grant nos. 20170623021TC and 20160414005GH) and Jilin University Bethune Plan B Projects (grant no. 2015222).

\section{Availability of data and materials}

All data generated or analyzed during this study are included in this published article.

\section{Authors' contributions}

YX conceived and designed the experiments, performed the experiments, analyzed the data and wrote the manuscript. WG, YZ and SW performed the experiments, and analyzed the data. YL, XD, JY, LX and HY analyzed the data, prepared figures and/or tables. JS and LS conceived and designed the experiments, and reviewed and edited the manuscript. All authors have read and approved the final manuscript.

\section{Ethics approval and consent to participate}

Not applicable.

\section{Patient consent for publication}

Not applicable

\section{Competing interests}

The authors declare that they have no conflict of interest.

\section{References}

1. Tew WP and Fleming GF: Treatment of ovarian cancer in the older woman. Gynecol Oncol 136: 136-142, 2015.

2. Jayson GC, Kohn EC, Kitchener HC and Ledermann JA: Ovarian cancer. Lancet 384: 1376-1388, 2014.

3. Gottesman MM, Fojo T and Bates SE: Multidrug resistance in cancer: Role of ATP-dependent transporters. Nat Rev Cancer 2: 48-58, 2002.

4. Holohan C, Van Schaeybroeck S, Longley DB and Johnston PG: Cancer drug resistance: An evolving paradigm. Nat Rev Cancer 13: 714-726, 2013.

5. Yu H, Su J, Xu Y, Kang J, Li H, Zhang L, Yi H, Xiang X, Liu F and Sun L: p62/SQSTM1 involved in cisplatin resistance in human ovarian cancer cells by clearing ubiquitinated proteins. Eur J Cancer 47: 1585-1594, 2011.

6. Ma L, Xu Y, Su J, Yu H, Kang J, Li H, Li X, Xie Q, Yu C, Sun L, et al: Autophagic flux promotes cisplatin resistance in human ovarian carcinoma cells through ATP-mediated lysosomal function. Int J Oncol 47: 1890-1900, 2015.

7. Xie Q, Su J, Jiao B, Shen L, Ma L, Qu X, Yu C, Jiang X, Xu Y and Sun L: ABT737 reverses cisplatin resistance by regulating ER-mitochondria $\mathrm{Ca}^{2+}$ signal transduction in human ovarian cancer cells. Int J Oncol 49: 2507-2519, 2016.

8. Lagadinou ED, Sach A, Callahan K, Rossi RM, Neering SJ, Minhajuddin M, Ashton JM, Pei S, Grose V, O'Dwyer KM, et al: BCL-2 inhibition targets oxidative phosphorylation and selectively eradicates quiescent human leukemia stem cells. Cell Stem Cell 12: 329-341, 2013.

9. Oltersdorf T, Elmore SW, Shoemaker AR, Armstrong RC, Augeri DJ, Belli BA, Bruncko M, Deckwerth TL, Dinges J, Hajduk PJ, et al: An inhibitor of Bcl-2 family proteins induces regression of solid tumours. Nature 435: 677-681, 2005.

10. Weiler M, Bähr O, Hohlweg U, Naumann U, Rieger J, Huang H, Tabatabai G, Krell HW, Ohgaki H, Weller M, et al: BCL-xL: Time-dependent dissociation between modulation of apoptosis and invasiveness in human malignant glioma cells. Cell Death Differ 13: 1156-1169, 2006.

11. Bae IH, Yoon SH, Lee SB, Park JK, Ho JN and Um HD: Signaling components involved in Bcl-w-induced migration of gastric cancer cells. Cancer Lett 277: 22-28, 2009.

12. Kelekar A and Thompson CB: Bcl-2-family proteins: The role of the BH3 domain in apoptosis. Trends Cell Biol 8: 324-330, 1998.

13. Manfredi G, Kwong JQ, Oca-Cossio JA, Woischnik M, Gajewski CD, Martushova K, D'Aurelio M, Friedlich AL and Moraes CT: BCL-2 improves oxidative phosphorylation and modulates adenine nucleotide translocation in mitochondria of cells harboring mutant mtDNA. J Biol Chem 278: 5639-5645, 2003.

14. Dey R and Moraes CT: Lack of oxidative phosphorylation and low mitochondrial membrane potential decrease susceptibility to apoptosis and do not modulate the protective effect of $\mathrm{Bcl}-\mathrm{x}(\mathrm{L})$ in osteosarcoma cells. J Biol Chem 275: 7087-7094, 2000.

15. Warburg O: Iron, the oxygen-carrier of respiration-ferment. Science 61: 575-582, 1925.

16. Warburg O: On the origin of cancer cells. Science 123: 309-314, 1956.

17. Chandel NS: Mitochondria and cancer. Cancer Metab 2: 8, 2014.

18. Matassa DS, Amoroso MR, Lu H, Avolio R, Arzeni D, Procaccini C, Faicchia D, Maddalena F, Simeon V, Agliarulo I, et al: Oxidative metabolism drives inflammation-induced platinum resistance in human ovarian cancer. Cell Death Differ 23: 1542-1554, 2016.

19. Ippolito L, Marini A, Cavallini L, Morandi A, Pietrovito L, Pintus G, Giannoni E, Schrader T, Puhr M, Chiarugi P, et al: Metabolic shift toward oxidative phosphorylation in docetaxel resistant prostate cancer cells. Oncotarget 7: 61890-61904, 2016. 
20. Denise C, Paoli P, Calvani M, Taddei ML, Giannoni E, Kopetz S Kazmi SM, Pia MM, Pettazzoni P, Sacco E, et al: 5-fluorouracil resistant colon cancer cells are addicted to OXPHOS to survive and enhance stem-like traits. Oncotarget 6: 41706-41721, 2015.

21. Montopoli M, Bellanda M, Lonardoni F, Ragazzi E, Dorigo P, Froldi G, Mammi S and Caparrotta L: 'Metabolic reprogramming' in ovarian cancer cells resistant to cisplatin. Curr Cancer Drug Targets 11: 226-235, 2011.

22. Fan Z, Yu H, Cui N, Kong X, Liu X, Chang Y, Wu Y, Sun L and Wang G: ABT737 enhances cholangiocarcinoma sensitivity to cisplatin through regulation of mitochondrial dynamics. Exp Cell Res 335: 68-81, 2015.

23. Livak KJ and Schmittgen TD: Analysis of relative gene expression data using real-time quantitative PCR and the 2(-Delta Delta C(T)) Method. Methods 25: 402-408, 2001.

24. Bol V, Bol A, Bouzin C, Labar D, Lee JA, Janssens G, Porporato PE, Sonveaux P, Feron O and Grégoire V: Reprogramming of tumor metabolism by targeting mitochondria improves tumor response to irradiation. Acta Oncol 54: 266-274, 2015.

25. Xiang XY, Kang JS, Yang XC, Su J, Wu Y, Yan XY, Xue YN, $\mathrm{Xu} \mathrm{Y}$, Liu YH, Yu CY, et al: SIRT3 participates in glucose metabolism interruption and apoptosis induced by $\mathrm{BH} 3$ mimetic S1 in ovarian cancer cells. Int J Oncol 49: 773-784, 2016.

26. Floreani M, Petrone M, Debetto P and Palatini P: A comparison between different methods for the determination of reduced and oxidized glutathione in mammalian tissues. Free Radic Res 26 : 449-455, 1997

27. Deberardinis RJ, Sayed N, Ditsworth D and Thompson CB: Brick by brick: Metabolism and tumor cell growth. Curr Opin Genet Dev 18: 54-61, 2008

28. Caneba CA, Yang L, Baddour J, Curtis R, Win J, Hartig S, Marini $J$ and Nagrath D: Nitric oxide is a positive regulator of the Warburg effect in ovarian cancer cells. Cell Death Dis 5: e1302, 2014.

29. Stanton RC: Glucose-6-phosphate dehydrogenase, NADPH, and cell survival. IUBMB Life 64: 362-369, 2012.

30. Borst P, Evers R, Kool M and Wijnholds J: A family of drug transporters: The multidrug resistance-associated proteins. J Natl Cancer Inst 92: 1295-1302, 2000.

31. Patra KC and Hay N: The pentose phosphate pathway and cancer. Trends Biochem Sci 39: 347-354, 2014

32. Köhler E, Barrach $H$ and Neubert D: Inhibition of NADP dependent oxidoreductases by the 6-aminonicotinamide analogue of NADP. FEBS Lett 6: 225-228, 1970

33. Raineri R and Levy HR: On the specificity of steroid interaction with mammary glucose 6-phosphate dehydrogenase. Biochemistry 9: 2233-2243, 1970.

34. Gross A: BCL-2 family proteins as regulators of mitochondria metabolism. Biochim Biophys Acta 1857: 1243-1246, 2016.

35. Caro P, Kishan AU, Norberg E, Stanley IA, Chapuy B, Ficarro SB Polak K, Tondera D, Gounarides J, Yin H, et al: Metabolic signatures uncover distinct targets in molecular subsets of diffuse large B cell lymphoma. Cancer Cell 22: 547-560, 2012.

36. Weinberg SE and Chandel NS: Targeting mitochondria metabolism for cancer therapy. Nat Chem Biol 11: 9-15, 2015

37. Vander Heiden MG, Cantley LC and Thompson CB Understanding the Warburg effect: The metabolic requirements of cell proliferation. Science 324: 1029-1033, 2009.

38. Berridge MV, Herst PM and Tan AS: Metabolic flexibility and cell hierarchy in metastatic cancer. Mitochondrion 10: 584-588, 2010.

39. Jose C, Hébert-Chatelain E, Bellance N, Larendra A, Su M, Nouette-Gaulain K and Rossignol R: AICAR inhibits cancer cell growth and triggers cell-type distinct effects on OXPHOS biogenesis, oxidative stress and Akt activation. Biochim Biophys Acta 1807: 707-718, 2011.

40. Roesch A, Vultur A, Bogeski I, Wang H, Zimmermann KM, Speicher D, Körbel C, Laschke MW, Gimotty PA, Philipp SE, et al: Overcoming intrinsic multidrug resistance in melanoma by blocking the mitochondrial respiratory chain of slow-cycling JARID1B(high) cells. Cancer Cell 23: 811-825, 2013.
41. Vander Heiden MG, Locasale JW, Swanson KD, Sharfi H, Heffron GJ, Amador-Noguez D, Christofk HR, Wagner G, Rabinowitz JD, Asara JM, et al: Evidence for an alternative glycolytic pathway in rapidly proliferating cells. Science 329 : 1492-1499, 2010.

42. Ahn CS and Metallo CM: Mitochondria as biosynthetic factories for cancer proliferation. Cancer Metab 3: 1, 2015.

43. Vander Heiden MG: Targeting cancer metabolism: A therapeutic window opens. Nat Rev Drug Discov 10: 671-684, 2011.

44. Lee YJ, Galoforo SS, Berns CM, Tong WP, Kim HR and Corry PM: Glucose deprivation-induced cytotoxicity in drug resistant human breast carcinoma MCF-7/ADR cells: Role of c-myc and bcl-2 in apoptotic cell death. J Cell Sci 110: 681-686, 1997.

45. Catanzaro D, Gaude E, Orso G, Giordano C, Guzzo G, Rasola A, Ragazzi E, Caparrotta L, Frezza C and Montopoli M: Inhibition of glucose-6-phosphate dehydrogenase sensitizes cisplatinresistant cells to death. Oncotarget 6: 30102-30114, 2015.

46. Wang Z, Fukushima H, Gao D, Inuzuka H, Wan L, Lau AW, Liu P and Wei W: The two faces of FBW7 in cancer drug resistance. BioEssays 33: 851-859, 2011.

47. Gorrini C, Harris IS and Mak TW: Modulation of oxidative stress as an anticancer strategy. Nat Rev Drug Discov 12: 931-947, 2013.

48. Sengupta N, Rose ST and Morgan JA: Metabolic flux analysis of $\mathrm{CHO}$ cell metabolism in the late non-growth phase. Biotechnol Bioeng 108: 82-92, 2011.

49. Polimeni M, Voena C, Kopecka J, Riganti C, Pescarmona G, Bosia A and Ghigo D: Modulation of doxorubicin resistance by the glucose-6-phosphate dehydrogenase activity. Biochem J 439: 141-149, 2011.

50. Wang J, Yuan W, Chen Z, Wu S, Chen J, Ge J, Hou F and Chen Z: Overexpression of G6PD is associated with poor clinical outcome in gastric cancer. Tumour Biol 33: 95-101, 2012.

51. Clément MV, Hirpara JL and Pervaiz S: Decrease in intracellular superoxide sensitizes $\mathrm{Bcl}-2$-overexpressing tumor cells to receptor and drug-induced apoptosis independent of the mitochondria. Cell Death Differ 10: 1273-1285, 2003.

52. Chen ZX and Pervaiz S: Bcl-2 induces pro-oxidant state by engaging mitochondrial respiration in tumor cells. Cell Death Differ 14: 1617-1627, 2007.

53. Chen ZX and Pervaiz S: Involvement of cytochrome c oxidase subunits $\mathrm{Va}$ and $\mathrm{Vb}$ in the regulation of cancer cell metabolism by Bcl-2. Cell Death Differ 17: 408-420, 2010.

54. Chen L, Willis SN, Wei A, Smith BJ, Fletcher JI, Hinds MG, Colman PM, Day CL, Adams JM and Huang DC: Differential targeting of prosurvival $\mathrm{Bcl}-2$ proteins by their $\mathrm{BH} 3$-only ligands allows complementary apoptotic function. Mol Cell 17: 393-403, 2005.

55. Dai Y, Jin S, Li X and Wang D: The involvement of Bcl-2 family proteins in AKT-regulated cell survival in cisplatin resistant epithelial ovarian cancer. Oncotarget 8: 1354-1368, 2017.

56. Semenza GL: HIF-1: Upstream and downstream of cancer metabolism. Curr Opin Genet Dev 20: 51-56, 2010.

57. Wang GL and Semenza GL: General involvement of hypoxiainducible factor 1 in transcriptional response to hypoxia. Proc Natl Acad Sci USA 90: 4304-4308, 1993.

58. Semenza GL: Defining the role of hypoxia-inducible factor 1 in cancer biology and therapeutics. Oncogene 29: 625-634, 2010.

59. Ai Z, Lu Y, Qiu S and Fan Z: Overcoming cisplatin resistance of ovarian cancer cells by targeting HIF-1-regulated cancer metabolism. Cancer Lett 373: 36-44, 2016.

This work is licensed under a Creative Commons Attribution-NonCommercial-NoDerivatives 4.0 International (CC BY-NC-ND 4.0) License. 